Hispania Sacra, Estudios de Edad Moderna, 58

117, enero-junio 2006, 101-141, ISSN: 0018-215-X

\title{
EL COLEGIO JESUÍTICO DE SAN JUAN BAUTISTA DE MONTERREI-VERÍN: MEMORIAL DEL PROCESO DE UNA EXPULSIÓN*
}

\author{
POR \\ José Ramón Hernández Figueiredo y José David Penín Martínez \\ Instituto Teológico «Divino Maestro» - Ourense
}

\section{RESUMEN}

El Colegio de Jesuitas de la villa de Monterrei, de la diócesis de Ourense, celebra el 450 aniversario de su fundación. Con motivo de esta efemérides se hace memoria de los principales momentos de su historia, especialmente de la expulsión de sus individuos y la apropiación de sus temporalidades.

PAlABRAS ClAVE: Jesuitas, Colegios, Monterrey, Expulsión, Temporalidades, Aniversario.

\begin{abstract}
The Jesuit school of the village of Monterrei, of the diocese of Ourense, celebrates the $450^{\text {th }}$ anniversary of its foundation. Because of this event, it is made memory of the main moments of its history, specially of the expulsion of its members and the consent of «temporalidades».
\end{abstract}

KEY WORDS: Jesuits, Schools, Monterrei, Expulsion, «Temporalidades», Anniversary.

\footnotetext{
* Siglas: $\mathrm{AC}=$ Archivo de Campomanes; $\mathrm{ACOu}=$ Archivo Capitular de Ourense; $\mathrm{AHDOu}=\mathrm{Ar}-$ chivo Histórico Diocesano de Ourense; AHN = Archivo Histórico Nacional; AHP = Archivum Historiae Pontificiae; $\mathrm{AHPOu}=$ Archivo Histórico Provincial de Ourense; AHSI = Archivum Historicum Societatis Iesu; ARSI = Archivum Romanum Societatis Iesu; ASV = Archivio Segreto Vaticano; $\mathrm{BCMO}=$ Boletín de la Comisión de Monumentos de Orense; BRAH = Boletín de la Real Academia de la Historia; MHSI = Monumenta Historica Societatis Iesu.
} 
Con motivo del 450 aniversario de la fundación del Colegio que la Compañía de Jesús erigió en Monterrei en la histórica comarca verinense y animados por el celo con que la Asociación de Antiguos Alumnos del Colegio Apóstol Santiago de Vigo ha llevado a término los preparativos para conmemorar esta efemérides, nos ha parecido bien contribuir a esta celebración desde el Instituto Teológico «Divino Maestro» de Ourense. Precisamente desde esta institución por tratarse del Seminario Diocesano, ya que sus primitivos cimientos descansan en el seminario pretridentino que fundó el obispo auriense y padre conciliar Francisco Blanco (1556-1565), centro educativo instalado en el Colegio de Monterrei bajo la sabia dirección de los padres jesuitas.

En este artículo no se pretende un estudio exhaustivo sobre la historia del Colegio, tarea ya realizada con una encomiable maestría por el padre Evaristo Rivera, sj, sino una referencia aproximativa a su origen y fundación para memorar aquella célebre data, así como el ofrecimiento de la trascripción detallada y crítica de un documento inédito hallado en el AHN que aporta mucha luz sobre uno de los acontecimientos más oscuros de la historiografía eclesiástica española hasta hace bien poco, como fue aquél de la expulsión de los jesuitas por el rey Carlos III. El seguimiento del fin de la Casa de Monterrei completará todavía más el conocimiento que se tiene de la extinción de la Compañía de Jesús en España.

\section{INTRODUCCIÓN}

El Colegio de Monterrei fue el primero que se creó en tierras galaicas y el último que aprobó San Ignacio de Loyola poco antes de su muerte. Había seguido de cerca los trámites de su fundación a través de una nutrida correspondencia. San Ignacio en sus primeros años había excluido la enseñanza como tarea de la Compañía, debiendo solamente proponer un anuncio simple y pobre, lejos de los fastos de las grandes cátedras y famosos púlpitos ${ }^{1}$. Debían tener casas de formación para ellos, pero no colegios o universidades. Pero las experiencias felices de los colegios de Gandía (1545) y de Messina (1546), indicaron el nuevo camino a seguir. Así a la muerte del fundador (1556) los ministerios principales de los jesuitas eran las misiones y los colegios ${ }^{2}$.

\footnotetext{
1 Para una breve síntesis sobre los inicios de la obra de san Ignacio y los jesuitas, cfr. Luigi MezZADRI, Storia della Chiesa. Tra Medioevo ed Epoca Moderna, II: Rinnovamenti, separazioni, missioni. Il Concilio di Trento (1492-1563), Roma: Centro Liturgico Vincenziano, 2001, pp. 69-81.

${ }^{2}$ La fuente principal está constituita por Monumenta Paedagogica Societatis Iesu, edidit, ex integro refecit novisque textibus auxit: I (1540-1556) y II (1557-1572), ed. Ladislas LUKÁCS, Romae: apud Monumenta Historica Societatis Iesu, 1965 y 1974. Cfr. Ricardo García Villoslada, Storia del Collegio Romano dal suo inizio (1551) alla soppressione della Compagnia di Gesù (1773), Roma: apud Aedes Universitatis Gregorianae, 1954; Pietro TACCHI VENTURI, L'Umanesimo e il fondatore del Collegio

Hispania Sacra, Estudios de Edad Moderna, 58

117, enero-junio 2006, 101-141, ISSN: 0018-215-X
} 
La Compañía fue fundada en Roma en el año 1540. Habían pasado sólo dieciséis años cuando los jesuitas establecieron un Colegio en la villa de Monterrei, en un rincón de Galicia, al Sur de la provincia ourensana. Si la instalación en Monterrei no tuvo excesivos problemas, la polémica surgió generalmente cuando los jesuitas decidieron instalarse en las ciudades: en Santiago, Ourense, Pontevedra y A Coruña, además de Monforte ${ }^{3}$. Y paradójicamente, la obstrucción surgió del seno de la propia Iglesia clerical, de los cabildos y de los conventos ya instalados. La razón es obvia: se presentaba una nueva Orden dispuesta a atraerse al pueblo hasta el momento ya repartido, y en la mentalidad de entonces se entendía que todo lo que la Compañía pudiera atraer a su causa significaba una merma de poder económico o social de los poderes eclesiásticos ya constituidos.

Pero las clases sociales más altas pensaban de otra forma. Veían en la Compañía no sólo una Orden muy selecta intelectualmente, sino además una nueva pastoral, una nueva forma de contactar con la realidad social y, sobre todo, nuevas respuestas a los problemas que la movilización social generaba. Su franca opción a favor del humanismo y la formulación de nuevos métodos pedagógicos tenían que atraer a las personas preocupadas por la formación de sus hijos ${ }^{4}$. $\mathrm{Su}$ personal ejemplaridad y disciplina contrastaban con la vida acomodaticia de

Romano, en AHSI 25 (1956), pp. 63-71; Ferdinando Trossarelli, Principi pedagogici della Compagnia di Gesù, en «La Civiltà Cattolica», 107/2 (1956), pp. 573-585 y 107/3 (1956), pp. 364-375; Pedro DE LETURIA, «La pedagogía humanista de san Ignacio y la España imperial de su época», en Estudios Ignacianos, I, ed. Ignacio IPARRAGUIRRE, Romae: Bibliotheca Instituti Historici Societatis Iesu, 1957, pp. 323-354; ID., «El Papa Paolo IV y la fundación del Colegio Romano», en ibid., pp. 389-400; Gabriel Codina Mir, Aux sources de la pédagogie des Jésuites: Le «modus Parisiensis», Roma: Institutum Historicum Societatis Iesu, 1968; Josep María BENíTEZ I RIERA, «En torno al método pedagógico jesuítico hasta 1773: fuentes y problemática», en Memoria Ecclesiae, XII (Oviedo, 1988), pp. 389421; José Ignacio Tellechea IDÍGORAS, Il Collegio Romano: «Omnium nationum seminarium». Prospettive e speranze ignaziane, en AHP 29 (1991), pp. 9-16; Cándido Pozo SÁNCHEZ, La facoltà di teologia del Collegio Romano nel XVI secolo, en ibid., pp. 17-32; Peter HeNRICI, L'insegnamento della filosofia, en ibid., pp. 33-41; Mario Fors, L'insegnamento delle lettere al Collegio Romano, en ibid., pp. 42-60; Bernabé BARTOLOMÉ MARTínez, Los colegios de jesuitas y la educación de la juventud, en Historia de la acción educadora de la Iglesia en España, I: Edades Antigua, Media y Moderna, Madrid: BAC, 1995, pp. 644-682.

${ }^{3}$ Cfr. sobre la instalación de los distintos colegios de la Compañía en Galicia: Evaristo RiverA VÁZQUEZ, Galicia y los jesuitas: sus colegios y enseñanza en los siglos XVI al XVIII, Ejercitación de Doctorado, La Coruña: Galicia Editorial, 1989; Antonio Astrain, Historia de la Compañía de Jesús de la asistencia de España, Madrid: Est. Tip. «Sucesores de Rivadeneyra», 1902, 7 vols.

4 Para el estudio del nuevo modo de hacer cultura, es decir, los colegios de los jesuitas, cfr. Ricardo García Villoslada, Storia del Collegio Romano dal suo inizio (1551) alla soppressione della Compagnia di Gesù (1773), Roma: apud Aedes Universitatis Gregorianae, 1954; Ferdinando TrossARELLI, Principi pedagogici della Compagnia di Gesù, en LaCivCatt 107/2 (1956), pp. 573-585 y 107/3 (1956), pp. 364-375; Pedro DE LETURIA, «La pedagogía humanista de san Ignacio y la España imperial de su época», en Estudios Ignacianos, I, ed. Ignacio IPARRAGUIRRE, Romae: Bibliotheca Instituti Historici Societatis Iesu, 1957, pp. 323-354; ID., «El Papa Paolo IV y la fundación del Colegio Romano», en 
los monasterios y muchos conventos. Su oratoria, directa y relacionada con la vida cotidiana, era perfectamente entendida por todas las clases sociales, que se sintieron atraídas desde el primer momento por la Compañía. El papel destacado por los teólogos jesuitas en las largas sesiones de Trento era conocido por los obispos asistentes, como Francisco Blanco, que no dudaron en prestar todo su apoyo a la nueva Orden para que se instalara en sus respectivas jurisdicciones. Al final los jesuitas conseguirán establecerse en Galicia protagonizando un capítulo fundamental en la historia de la ciencia al educar a miles de jóvenes en sus aulas.

Como anota Miquel Batllori, las fundaciones de los colegios de la Compañía solían provenir de tres ámbitos: el pontificado, los cabildos municipales y personalidades señaladas, como obispos, príncipes, soberanos y otros personajes $^{5}$. En el caso de Monterrei, tenemos una fundación de iniciativa episcopal, si bien su realización se alcanzará con ayuda de otras personas e instituciones ${ }^{6}$.

\section{El Colegio de Monterrei}

Este primer Colegio de la Compañía ${ }^{7}$ en la diócesis de Ourense fue posible gracias a la coincidencia de varias personalidades muy cercanas a los jesuitas: el tercer conde de Monterrei, Alonso de Acevedo y Zúñiga, humanista y protector de las ciencias y que, por residir en Valladolid, no sólo conocía la obra de la Compañía sino que además había entablado amistad con san Francisco de Bor-

ibid., pp. 389-400; Gabriel CoDINA MIR, Aux sources de la pédagogie des Jésuites: Le «modus Parisiensis», Roma: Institutum Historicum Societatis Iesu, 1968; Josep María BENÍTEZ I RIERA, «En torno al método pedagógico jesuítico hasta 1773: fuentes y problemática», en Memoria Ecclesiae, XII (1988), pp. 389-421; José Ignacio TellecheA Idígoras, Il Collegio Romano: «Omnium nationum seminarium». Prospettive e speranze ignaziane, en AHP 29 (1991), pp. 9-16; Bernabé BARTOLOMÉ MARTÍNEZ, Los colegios de jesuitas y la educación de la juventud, en Historia de la acción educadora de la Iglesia en España, I: Edades Antigua, Media y Moderna, Madrid: BAC, 1995, pp. 644-682.

5 Miquel Batllori, Cultura e finanze. Studi sulla storia dei gesuiti da S. Ignazio al Vaticano II, Roma: Edizioni di Storia e Letteratura, 1983, pp. 121-138.

${ }^{6}$ Cfr. Ofelia Rey Castelao, El clero regular, en Historia de las diócesis españolas, XV: Iglesias de Lugo, Mondoñedo-Ferrol y Orense, ed. José García Oro, Madrid: BAC, 2002, pp. 523-529.

7 Cfr. Jesús TABoAda ChIVITE, Los tres conventos de Monterrey, en BCMO XVII, fasc. III (enerodiciembre 1951), pp. 245-262; ID., Monterrey, Santiago de Compostela: Instituto Padre Sarmiento de Estudios Gallegos, 1960, pp. 80-83; Luis DE VALDIVIA, Pleitos sobre el Señorío de Monterrey, en BCMO IX, 201 (noviembre-diciembre 1931), pp. 273-280; ID., Colegios de los Jesuitas en Galicia: Colegio de Monterrey, en BCMO IX, 204 (mayo-junio 1932), pp. 348-356; 206 (septiembre-octubre 1932), pp. 397-404; 207 (noviembre-diciembre 1932), pp. 425-428; X, 208 (enero-febrero 1933), pp. 25-29; además es preciso señalar Antonio Astrain, Historia de la Compañía de Jesús de la asistencia de España, I: San Ignacio de Loyola 1540-1556, o. c., pp. 412-437, y la ya citada tesis doctoral del jesuita Evaristo RIVERA VÁZQUEZ, Galicia y los jesuitas: sus colegios y enseñanza en los siglos XVI al XVIII, o. c., pp. 53-103.

Hispania Sacra, Estudios de Edad Moderna, 58

117, enero-junio 2006, 101-141, ISSN: 0018-215-X 
ja, superior de todos los conventos jesuitas de España ${ }^{8}$; y Francisco Manrique de Lara (1542-1556), obispo de Ourense, amigo personal de san Ignacio de Loyola y conocedor, por su asistencia en Trento, de la ciencia de los jesuitas ${ }^{9}$. Únase a esto el hecho de que el sucesor de Manrique de Lara en Ourense fue el obispo Francisco Blanco (1556-1565), otro entusiasta de la Compañía.

Este prelado ${ }^{10}$, que había llegado a la diócesis en 1556 , no contento con favorecer y estimar a los estudiantes que se formaban en Monterrei y seguían después su vocación sacerdotal, quiso establecer allí mismo un centro especial donde se preparasen algunos alumnos escogidos por él para atender las necesidades de su diócesis. Aquel pequeño Colegio fue un Seminario formal del obispado de Ourense ${ }^{11}$, cinco años antes de que viese la luz el decreto Cum adolescentium aetas. Se trataría de lo que hoy llamamos un Colegio residencial, con régimen de internado, gobierno propio y formación escolar en el Colegio de la Compañía. Francisco Blanco estimó hondamente este pequeño seminario suyo de Monterrei a la hora de admitir a las órdenes a algún alumno:

El Obispo de este obispado, que es de Orense — se dice en una carta a Roma en 1558es tan nuestro hermano, que a todos los de este Colegio ordena y no a otros. Y a todos los envía a estudiar a este Colegio y comete muchos negocios al P. Rector y muy graves, que tocan a la gobernación espiritual de su obispado ${ }^{12}$.

El obispo Francisco Blanco no sólo creó el pequeño seminario de Monterrei y apoyó al Colegio, que era la base de aquél, sino que también trabajó con todo empeño para fundar otro en Ourense ${ }^{13}$. No pudo ser. La colaboración de la

${ }^{8}$ Había sido marqués, duque y virrey Cataluña antes de hacerse jesuita. Será el tercer General de la Orden.

9 Sobre este obispo, cfr. Constancio GuTIÉRREZ, Españoles en Trento, Valladolid: Instituto Jerónimo Zurita sección de Historia Moderna Simancas, 1951, pp. 411-415. Padre conciliar en Trento, y obispo de Ourense, Salamanca y Sigüenza, sucesivamente.

${ }^{10}$ Cfr. Conradus Eubel, Hierarchia Catholica, III, p. 124; Constancio GutiÉRrez, Españoles en Trento, o. c., pp. 383-395.

11 José Ramón Hernández Figueiredo, El Seminario Conciliar de San Fernando de Ourense (1804-1952). Historia de una institución de piedad y cultura, Ejercitación de Doctorado, Ourense: Diputación Provincial, 2004, pp. 116-118.

12 Evaristo RIVERA VÁZQUEZ, Galicia y los jesuitas: sus colegios y enseñanza en los siglos XVI al XVIII, o. c., p. 539, que recoge la carta de Paulo Hernández a Laínez. Monterrey, 4 de febrero de 1558, en MHSI, Litterae quadrimestres, V, p. 539.

13 Prueba de ello, es la carta que dirige a Laínez, mostrando en el texto, con un cierto gracejo, una gran simpatía por la Compañía: «fue N. Sr. servido de ponerme en estado, que me obliga a emplearme en ayudar a otros, porque todos consigamos lo que Dios nos ha prometido. Y porque yo solo no basto para esto, deseo alguna buen compañía, y deseo que esta fuese la de Jesús, cuyo instituto, según tengo entendido, es éste. Y aunque tengo un colegio de la Compañía en mi obispado, en la villa de Monterrey, quería otro para la çiudad de Orense, que está de allí diez leguas», en El Obispo de Orense, Francisco Blanco, a Laínez. Valladolid, 31 de mayo de 1559, en ARSI, Laínez, IV, fols. 372-373. 
Compañía la procuró intensamente, a la vez que los elogios de los jesuitas hacia la persona de su obispo no se hacen esperar, por su estima a la Orden y su caridad con los estudiantes pobres.

Para asegurar la sustentación del convento, y aparte de la dotación del conde, se asignaron al mismo las rentas en sus dos terceras partes de cinco benefi$\operatorname{cios}^{14}$, sobre los cuales y desde hacía tiempo disputaban tanto el obispo como el conde sobre el derecho de presentación de los mismos. Se comprometía asimismo la Compañía a tener en el Colegio 23 individuos, entre los cuales había dos lectores de Gramática, uno de Artes y otro de Teología. La escritura de la fundación del Colegio se firmó en Santiago en 1555 y, en la primavera del año siguiente, llegaron a Monterrei los primeros jesuitas, viviendo todavía San Ignacio $^{15}$. Los mismos prelados llegarían a considerar este Colegio como el centro más importante de educación cristiana e irradiación pastoral que tenían en la diócesis ${ }^{16}$. Al respecto, es indicadora la siguiente noticia que el rector, P. Valderrábano, comunicaba al P. General en el año 1562:

\begin{abstract}
Hacen dos maestros gran provecho en la clase, así en el aprovechamiento de las letras como de las virtudes; tanto, que en los obispados de este reino se tiene por legítima consecuencia: es de Monterrey, luego bien le podemos dar órdenes. Y con razón: porque la principal reformación de este reino pendía de los clérigos, y ven claramente el fruto que hacen los estudiantes de este colegio después de ordenados, así con su vida y ejemplo como con doctrina. Y es verdad, que van algunos del pueblo á oir misa muchas veces, como ellos dicen, sólo por verlos estar en misa tan sosegados, hincados de rodillas, los rosarios en las manos, que mueven á devoción; y más mueve á los que conocen á los padres, viendo los hijos tan otros, con sus rosarios en las cintas, tan modestos. Suelen los que vienen de fuera, como curas ú otras personas principales, ponerse á la puerta de la iglesia á contarlos, y hallando tan gran número, dan gracias innumerables al que los juntó ${ }^{17}$.
\end{abstract}

Mientras tanto, el conde de Monterrei había fracasado en su intento de convertir la Universidad de Santiago en una universidad jesuítica. Pero no por ello

\footnotetext{
14 Eran los beneficios de San Salvador de Vilaza, San Andrés de Guillamil, San Pedro de Queizás, Santa María de Tamagos y Santa María de Mandín. Cfr. Apuntación que parecio conveniente hacer para suplir las noticias, que no se hallen en el testimonio de los autos: y para conocimiento de algunos puntos, con que tiene conexion la pretension de los Abades, en ACOu, Documentos-Seminario, s. c., n. 2. Aquí se da información detallada de la fundación y de los beneficios percibidos por estos curatos para el sostenimiento de dicho convento.

15 Antonio Astrain, Historia de la Compañía de Jesús de la asistencia de España, I: San Ignacio de Loyola 1540-1556, o. c., p. 437.

16 Evaristo RIVERA VÁZQUEZ, Galicia y los jesuitas: sus colegios y enseñanza en los siglos XVI al XVIII, o. c., p. 79.

17 Carta del P. Valderrábano, rector del Colegio de Monterrei, a Laínez, en ARSI, Epistolae Hispaniae, IV, fol. 372r. Cita recogida de Antonio Astrain, Historia de la Compañía de Jesús de la asistencia de España, II: Laínez-Borja 1556-1572, o. c., pp. 574-575.
}

Hispania Sacra, Estudios de Edad Moderna, 58

117, enero-junio 2006, 101-141, ISSN: 0018-215-X 
renunciaba a la idea de crear una universidad en Galicia para los jesuitas. Lo intentó en Monterrei. Su muerte en 1559 impidió llevar adelante la idea, pero su esposa doña Inés de Velasco Tovar, mujer excepcional que quiso vivir siempre al lado del Colegio, donde envió a sus hijos, consigue firmar un convenio con la Compañía en virtud del cual el Colegio quedaba constituido en universidad. El general de la Compañía que era san Francisco de Borja, aprobó en Roma el convenio, que no pudo sin embargo realizarse por la muerte de la condesa además de los obstáculos económicos que frenaban la realización de este proyecto al ser necesaria una generosa dotación para tan importante número de catedráticos. De haberse logrado, sería la segunda universidad para Galicia después de la de Santiago, que había empezado a funcionar pocos años antes, en 1555. No hubo después, hasta nuestros días, un intento semejante. Sin duda, el planificar y reivindicar el título de Universidad para el Colegio de Monterrei constituía un hecho insólito y asombroso en la Galicia del siglo XVI ${ }^{18}$.

Las cátedras fueron las de Gramática, Humanidades, Artes o Filosofía y Teología Moral. El renombre de aquel centro se divulgó por los estados del Conde y aun por la frontera portuguesa. En aquel primer curso subieron a Monterrei 53 alumnos de la villa de Verín y de los alrededores, curiosos y expectantes ante el fenómeno que acababa de aparecer. Poco a poco fueron acercándose muchos más, «atraídos por una escuela de aquel tipo: inusitada, pluriforme, abierta a todo tipo de alumnos y, además, gratuita» ${ }^{19}$. No podemos fijar el número de catedráticos, pero todo hace pensar que hubo que doblar varias cátedras, si son correctas las cifras que los autores dan sobre el número de alumnos. El padre Nadal, en carta al General de la Compañía del 4 de mayo de 1561 , refería que contaban ya con más de trescientos escolares ${ }^{20}$, cifra que se ha de mantener en $1605^{21}$. El lugar era insuficiente, y a los pocos años de su fundación se pasaron «a un quarto de casa largo, que estaba pegado a los muros de la villa por la parte que mira al Occidente». En 1566, dice el padre Val-

18 Evaristo Rivera VÁzQUEZ, Galicia y los jesuitas: sus colegios y enseñanza en los siglos XVI al XVIII, o. c., pp. 161-169.

19 ID., El memorable Colegio que hubo en Monterrei, nota de prensa que agradezco a la Asociación de Antiguos Alumnos del Colegio Apóstol Santiago de Vigo.

20 Jesús TABoada Chivite, Monterrey, o. c., p. 80. Mientras que Antonio Astrain, Historia de la Compañía de Jesús de la asistencia de España, III: Mercurian-Aquaviva (primera parte) 1573-1615, o. c., p. 197, nos dice: «Monterrey contaba cuatrocientos gramáticos y doscientos de leer y escribir», en torno al año 1577.

21 Cfr. ASV, Congr. Concilio, Relat. Dioec., Aurien, busta 96 A, fol. 17r: «adest in civitate Schola Publica in qua Lingua Latina docetur et leguntur casus conscientiae in loco di Monterrey discipulos et leguntur in quodam Collegio Jhesuitarum quod fuit ab episcopis Auriensis predecessoribus fundatur et a Commite de Monterrey: regulariter numerus Audientiam accudit ad trecentos et ultra». Se trata de la relación presentada el 20 de julio de 1605, por el bachiller Juan de Albán y Quevedo, rector de la iglesia de Santa María de Sagra, actuando como procurador en nombre del obispo Miguel Ares de Canabal (1595-1611). 
divia que «se comenzó a cercar este monte y a edificar la casa que ahora tene$\operatorname{mos} »^{22}$.

De lo que no cabe duda es de que la Compañía quiso prestigiar este Colegio, destinando a él, por algún tiempo, grandes maestros, ya que en este Colegio consta que impartieron clases el padre Paulo Hernández, confesor de Santa Teresa; el padre Gaspar Astete, universal catequista, recibiendo en este centro el sacramento del Orden; el famoso padre Alonso Rodríguez, maestro de novicios y autor de una obra maestra de literatura religiosa Ejercicio de perfección y virtudes cristianas, que tanto inspiró a Unamuno, y de otras muchas obras importantes; el padre Juan Álvarez Sotelo, natural de Perrelos (Xinzo de Limia), autor de varias obras, entre ellas una inédita y valiosa Historia de Galicia, que citan Murguía y otros autores... Tampoco se puede olvidar a dos rectores del Colegio, los jesuitas Juan Bautista Segura y Pedro Martínez, quienes marcharon en diversos momentos como misioneros a la Florida, donde dieron la sangre por su $\mathrm{fe}^{23}$.

Resultado de esta selecta nómina de profesores fue el elevado número de alumnos que destacaron por su ciencia o por su vida, como Francisco Araújo, teólogo, catedrático de Salamanca y obispo de Segovia; Mauro Castellá Ferrer, alumno de Fr. Luis de León en Salamanca, soldado de la Invencible y autor de la Historia del Apóstol de Jesús Christo, Santiago Zebedeo, Patrón y Capitán General de las dos Españas; Diego de Torres, padre jesuita y futuro iniciador de las reducciones del Paraguay; San Francisco Blanco, franciscano, mártir del Japón, que estudió Gramática en este Colegio; el beato Pedro Vázquez, dominico, natural de Verín, alumno de Humanidades en el mismo centro, martirizado igualmente en tierras japonesas ${ }^{24}$.

Con luces y sombras la obra prosiguió su increíble itinerario. La guerra hispano-portuguesa (1640-1648) al igual que otros brotes bélicos a comienzos del siglo XVIII y una fuerte epidemia de peste le perjudicaron notablemente. Toda esta inmensa obra desapareció en 1767 con la aplicación de la famosa Pragmática de Carlos III que dejó el Colegio desierto para siempre. La iglesia pasó a cargo de los padres franciscanos, su biblioteca a la Universidad de Santiago, y sus cuadros y obras artísticas fueron dispersas, entre las que sobresale la excelente escultura del «Cristo de las Batallas» llevada por manos piadosas a la pa-

\footnotetext{
22 Luis de Valdivia, Colegios de los Jesuitas en Galicia: Colegio de Monterrey, art. c., 204 (mayo-junio 1932), pp. 348-356; 206 (septiembre-octubre 1932), pp. 397-404; 207 (noviembre-diciembre 1932), pp. 425-428; X, 208 (enero-febrero 1933), pp. 25-29. Aquí encontramos interesantes referencias sobre la fundación y dotación del nuevo Colegio, de los primeros rectores, del seminario pretridentino de Francisco Blanco, y de la escuela de niños.

23 Jesús TABoada Chivite, Monterrey, o. c., pp. 81-83.

24 Sobre los dos últimos, ambos mártires ourensanos, cfr. Cesáreo GIL ATRIO, Santos gallegos, Santiago de Compostela: Porto, 1976, pp. 79-97 y 123-135, respectivamente.
} 
rroquia de Verín. Las ruinas del Colegio sirvieron para embaldosar las calles, prestando lo que había sido un gran Colegio su último y humilde servicio ${ }^{25}$.

\section{LA EXPULSIÓN DE LOS JESUITAS}

El gobierno establecido por Carlos III en España es uno de los modelos más acabados del despotismo ilustrado ${ }^{26}$. De esta manera, el Estado, con el ansia de innovación en que lo iba envolviendo todo, no distingue límites y entra de lleno por el campo eclesiástico como por terreno propio, tratando de aligerarle de viejos resabios, para hacerlo más acomodado a las exigencias de los nuevos tiempos. Lo triste es que, no pocas veces, esas intervenciones se vendrán resintiendo de un cierto aspecto de laicismo exaltado, o bien de una especie de regalismo y cesaropapismo, barnizado de sabias y prudentes razones. En este ámbito se mueven tanto Carlos III como Carlos IV, pero sobre todo el primero ${ }^{27}$.

\footnotetext{
25 Noticia relativa a estos sucesos se encuentra en AHN, Clero: jesuitas, leg. 181, nn. 2-3 (certificaciones 1788-1796, del escribano de Monterrei y del de Verín, sobre aplicación de la Iglesia y Colegio de los Jesuitas de Monterrei, y sobre las deudas que han quedado de la Botica del mismo); nn. 4-5 (comunicaciones 1767-1789, de los comisionados y administradores de las Temporalidades de Monterrei, sobre aplicación de bienes, cátedras y otros asuntos de las mismas); leg. 182, nn. 1-3 (comunicaciones 1789-1819, de los comisionados y administradores de las Temporalidades de Monterrei, sobre aplicación de bienes, Obra Pía de Grijoa y otros asuntos de dichas Temporalidades); leg. 806, nn. 1-2 (cuentas 1767-1789, de las Temporalidades de este Colegio, dadas por los administradores de las mismas); nn. 3-9 (expedientes 1768-1769, sobre el Patronato del Mayorazgo de Grijoa, aplicación de bienes del Colegio y otros asuntos de las Temporalidades del mismo); leg. 807, nn. 1-18 (expedientes 1769, sobre el envío a Madrid de cuentas y autos de extrañamiento, oposición a Cátedras, almonedas, aplicación de la Iglesia y Colegio, y rentas a los religiosos de San Francisco); nn. 19-25 (instancias 1789-1793, de varias Iglesias, y Conventos, solicitando libros, ornamentos, alhajas y vasos sagrados de las Temporalidades de Monterrei; otras peticiones a las mismas de varios particulares); n. 26 (procesos, s. a., resumen del proceso sobre la expulsión de los Jesuitas); n. 27 (recibos 1768-1782, de pagos hechos por diversos conceptos por las Temporalidades).

${ }^{26}$ Carlos Seco Serrano, Carlos III: semblanza de un rey ilustrado. El monarca y su entorno, en BRAH CLXXXV / III (1988), pp. 425-445. Cfr. Roberto FERnÁNDEZ DíAZ, Carlos III, Madrid: Arlanza Ediciones, 2001, una de las últimas biografías sobre este rey ilustrado. Es interesante la bibliografía que allí se presenta.

27 Premisa historiográfica: tanto la persona como la política de Carlos III han sido diversamente juzgadas por la historiografía. Una gran corriente historiográfica, que parte de finales del siglo XIX hasta los años 40, ha experimentado la influencia de las tesis de Marcelino Menéndez y Pelayo. Carlos III habría sido un rey muy negativo para España por el hecho de introducir el «siglo francés», la cultura francesa, que no era propiamente española. A esto añaden la funesta expulsión de los jesuitas. Representativos de esta orientación son Fita, Lafuente, García Villada y García Villoslada. Ven en Carlos III un rey dominado por los ilustrados, los masones y los antiespañoles. Sin embargo, esta corriente ha sido superada al profundizarse en aspectos sociales, demográficos y culturales, coincidiendo sobre todo con las celebraciones ante el segundo centenario de la muerte del monarca. Se demuestra que fue un rey típico de aquella época, de tal modo que un bibliógrafo como Aguilar Piñal ha llegado a recopilar 8.400 fichas bibliográficas de trabajos publicados hasta 1995. Cfr. Francisco AguILAR Piñal, Bi-
} 
Todavía hoy en día no están absolutamente claras las causas que originaron la Real Pragmática, por la que la Compañía de Jesús quedaba disuelta en los dominios de la monarquía católica en España, Indias y Filipinas, y sus miembros expulsados de estos reinos. A pesar de los numerosos estudios, algunos de ellos publicados recientemente teniendo como base el archivo de Campomanes ${ }^{28}$, los motivos de esta expulsión habría que atribuirlos a un cúmulo de circunstancias $^{29}$, que partiendo del jansenismo ${ }^{30}$ y continuando con la política regalista de Carlos III y sus ministros y con los antecedentes de la expulsión de Portugal y Francia ${ }^{31}$ llegan a su punto culminante con las distintas alteraciones del orden público producidas prácticamente en todo el territorio peninsular, y especialmente en el acaecido en Madrid, conocido como Motín de Esquilache, con el cerco del propio rey en el palacio de Oriente ${ }^{32}$.

Poco a poco se fue constituyendo el Consejo Extraordinario. La elección de los distintos consejeros, hecha por el propio Campomanes, se debió fundamentalmente a su enemistad con los jesuitas, lo que evitó oposición y pareceres contrarios a la expulsión ${ }^{33}$. Una vez recibido el fatal dictamen, el rey aprueba las líneas generales de la exposición del Consejo Extraordinario y nombra al conde de Aranda comisionado especial, con todas las facultades para llevar a cabo las providencias necesarias para el extrañamiento ${ }^{34}$. La «Pragmática Sanción» del 2 de abril de 1767, por la que se decreta la expulsión de los miembros

bliografía de autores del siglo XVIII, Madrid: CSIC, 1981-1986, 4 vols.; ID., Bibliografía de autores españoles del siglo XVIII, Madrid: Consejo, Instituto Miguel de Cervantes, 1981, 4 vols. (A-B, C-Ch, D-F, G-K).

28 Pedro Rodríguez de Campomanes, Dictamen fiscal de expulsión de los jesuitas de España (1766-1767), ed. Jorge CEJUdo - Teófanes EGIDO, Madrid: FUE, 1977; Teófanes EGIDO - Isidoro PINEDO, Las causas "gravísimas» y secretas de la expulsión de los jesuitas por Carlos III, Madrid: FUE, 1994.

${ }^{29}$ Cfr. Teófanes EgIDo LóPEZ, Oposición radical a Carlos III y expulsión de los jesuitas, en BRAH CLXXIV / III (1977), pp. 529-545; Miquel BATLLORI, Cultura e finanze. Studi sulla storia dei gesuiti da S. Ignazio al Vaticano II, o. c., pp. 265-340; Giacomo MARTinA, Storia della Chiesa. Da Lutero ai nostri giorni, II: L'età dell'assolutismo, Brescia: Morcelliana, 1994, pp. 305-321; Josep María BENíteZ I RIERA, L'expulsió dels jesuïtes d'Espanya en temps di Carles III, en Expulsions $i$ Exilis, ed. Pere BALAÑ̇̀ I ABADIA et al., Roma: Associació «Catalans a Roma», 1996, pp. 46-68.

${ }^{30}$ Cfr. Giacomo Martina, Storia della Chiesa. Da Lutero ai nostri giorni, II: L'età dell'assolutismo, o. c., pp. 209-258.

31 Ibíd., pp. 279-304.

32 Sobre los motines en Madrid: Laura RodRíGUEZ DíAZ, «El Motín en Madrid de 1766», en Revista de Occidente, 121 (1973), pp. 24-49; Teófanes EGIDO LóPEZ, «Madrid, 1766: motines de corte y oposición al Gobierno», en Cuadernos de Investigación Histórica, 3 (1979), pp. 125-154; ID., «Motines contra Esquilache y religiosidad de los madrileños», en XX Siglos, III, 3 (1992), pp. 120-127.

33 Para el análisis de los nombramientos del Consejo ver: Teófanes EGIDO - Isidoro PINEDO, Las causas «gravísimas» y secretas de la expulsión de los jesuitas por Carlos III, o. c., pp. 26-37.

${ }^{34}$ Respuesta de Carlos III a la Consulta del Consejo Extraordinario, en AC 45 - 5. Sin fecha. Citado en ibíd., pp. 60-61.

Hispania Sacra, Estudios de Edad Moderna, 58

117, enero-junio 2006, 101-141, ISSN: 0018-215-X 
de la Compañía de España y sus Indias, aunque nada o poco explícita en cuanto a las causas de ésta, fija las necesarias providencias para llevarla al mejor término posible ${ }^{35}$. No hace otra cosa que aplicar el contenido del Real Decreto de Expulsión, con fecha del 27 de febrero de 1767, que reza así:

Real Decreto de Execucion: Habiendome conformado con el parecer de los de mi Consejo Real en el extraordinadio, que se celebra con motivo de las ocurrencias pasadas, en consulta de veinte y nueve de Enero proximo; y de lo que sobre ella me han expuesto personas del mas elevado carácter: estimulado de gravisimas causas, relativas á la obligacion en que me hallo constituido de mantener en subordinacion, tranquilidad y justicia mis Pueblos, y otras urgentes, justas y necesarias, que reservo en mi Real ánimo: usando de la suprema autoridad económica, que el Todo-Poderoso ha depositado en mis manos para la proteccion de mis Vasallos, y respecto de mi Corona: He venido en mandar se estrañen de todos mis Dominios de España, é Indias, Islas Filipinas, y demás adyacentes á los Religiosos de la Compañía (...); y que se ocupen todas las temporalidades de la Compañia en mis Dominios (...); y dareis para ello las Ordenes, é Instrucciones necesarias, acompañando exemplares de este mi Real Decreto, á los quales, estando firmados de Vos, se les dará la misma fe y crédito que al original. = Rubricado de la Real Mano. = En el Pardo, á veinte y siete de Febrero de mil setecientos sesenta y siete. $=$ Al Conde de Aranda. Presidente del Consejo ${ }^{36}$.

La expulsión se había preparado con todo sigilo y se llevó a cabo en Madrid en la noche del 31 de marzo al 1 de abril, y en la siguiente del 2 de abril en las demás provincias. A nadie se le escapa que la repercusión que se sigue de la expulsión de los jesuitas es notable. No en vano se plantea la operación con la mira puesta en estas temporalidades casi con el mismo interés que en las personas, y sería incauto creer que el general asentimiento de la jerarquía no obedeciese en buena parte a las expectativas sobre los bienes de la considerada como riquísima Compañía. Las transferencias, de hecho, beneficiaron tanto a las diócesis como al Estado. En consecuencia, los prelados se apresuran a pedir al rey las casas que los jesuitas tenían en sus diócesis ${ }^{37}$.

35 Pragmatica Sancion de S. M. en fuerza de Ley para el extrañamiento de estos Reynos á los Regulares de la Compañía, ocupacion de sus Temporalidades, y prohibicion de su restablecimiento en tiempo alguno, con las demás precauciones que expresa, Madrid 1767, fol. 3v, en donde se indica que los bienes de la Compañía se habían de dedicar a la dotación de parroquias pobres, seminarios conciliares, casas de misericordia... Cfr. José Antonio Ferrer BenIMELI, Carlos III y la extinción de los jesuitas, en Actas del Congreso Internacional sobre «Carlos III y la Ilustración», I: El rey y la monarquía, ed. Miguel ARTOla Gallego et al., Madrid: Ministerio de Cultura en colaboración con el CSIC, 1989, pp. 239-259; ID., La expulsión y extinción de los jesuitas según la correspondencia diplomática francesa, Zaragoza: Universidad de Zaragoza, 1993, 1996 y 1998, 3 vols.

${ }^{36}$ Coleccion del Real Decreto de 27 de Febrero de 1767, para la Egecucion del Extrañamiento de los Regulares de la Compañia, cometido por S. M. al Excmo. Sr. Conde de Aranda, como Presidente del Consejo: de las Instrucciones, y Ordenes succesivas dadas por S. E. en el cumplimiento; y de la Real Pragmática Sancion de 2 de Abril, en fuerza de Ley, para su observancia [fiel trascripción del título], Madrid: Imprenta Real de la Gazeta, 1767, en AHN, Consejos, lib. 1484, n. 8, fols. 25r-38r.

37 AHN, Consejos, leg. 8031, nn. 1 a 136, que contiene 136 Reales Cédulas y Despachos del Con- 


\section{El CierRe DEL Colegio}

Al tiempo de la expulsión, pasaban de cien los colegios jesuíticos de España, distribuidos por toda la geografía nacional. Uno de ellos era el de Monterrei, situado en la atalaya de un valle maravilloso, por donde los campos de Galicia se alargan hacia Portugal y suben hasta Castilla. La inigualable colina regiomontana era bien conocida como fortaleza estratégica, en la raya con Portugal, como sede de una ilustre casa nobiliaria y por ser posiblemente el lugar que albergó la primera imprenta que hubo en Galicia. A estas glorias indudables habría que añadir, en justicia, el sorprendente fenómeno cultural derivado del Estudio que allí establecieron la Casa de Monterrei y la Compañía de Jesús, hace casi cinco siglos.

Del edificio material ya no queda nada. Ni siquiera las venerables ruinas. Quien asciende a Monterrei, y contempla el grandioso panorama que sirve de marco, siente en el alma que no se mantengan en pie los muros del Colegio, para poder evocar, con más exactitud, los viejos recuerdos y la gloriosa historia. Al menos nos queda el consuelo de poder acudir al importante fondo documental que sobre este episodio se conserva en el Archivo Histórico Nacional de Madrid, en el Archivum Romanum Societatis Iesu de Roma, en los Archivos Histórico Provincial, Diocesano y Catedralicio de Ourense.

Sobre el particular de la expulsión de los jesuitas de Monterrei, apenas se puede apreciar publicación alguna a no ser el minucioso trabajo del padre Rivera que al haberse dedicado a la actividad de los colegios jesuíticos de Galicia entre los siglos XVI y XVIII, toca por encima este aspecto ${ }^{38}$. Tampoco se ha de olvidar un artículo de don Emilio Duro, ilustre archivero de la Catedral de $\mathrm{Ou}-$ rense, que evoca, en íntimos detalles, un apartado de aquel suceso violento, el que se refiere a los papeles privados y libros manuscritos de este Colegio ${ }^{39}$. Aquí presentaremos el escueto testimonio del padre Isla sobre lo acaecido, la relación de los jesuitas que residían en esta casa al momento de la expulsión, además de la trascripción que recoge el proceso de su extinción en Monterrei, secundado de un importante aparato crítico para poder ampliar su estudio.

El día primero de abril, gracias a la rapidez y sigilo del conde de Aranda, sonó el bombazo en todas las residencias de jesuitas de la península, unos 142 institutos (noviciados, casas de residencia, colegios), y a las veinticuatro horas salían unos 2.700 jesuitas españoles hacia los puertos en que habían de embar-

\footnotetext{
sejo Extraordinario sobre la aplicación y destino de las Iglesias y Colegios que fueron de los Regulares de la Compañía, correspondiente a los meses de Julio y Agosto de 1769. Son copias manuscritas.

38 Evaristo RIVERA VÁZQUEZ, Galicia y los jesuitas: sus colegios y enseñanza en los siglos XVI al XVIII, o. c., pp. 53-103.

39 Emilio Duro PeÑa, «Papeles privados y libros manuscritos del Colegio de Monterrey», en $\mathrm{Hu}$ manidades XV, 35 (Comillas, 1959), pp. 156-173.
} 
carse camino de Italia ${ }^{40}$. Aquí en Monterrei, como en todas las demás poblaciones, dejaban sus iglesias, sus residencias, sus libros, todo... Expone el padre José Francisco de Isla los detalles de la dramática situación padecida por los siete jesuitas prisioneros que habitaban en Ourense, siendo acompañados por diez vigilantes hasta el puerto de A Coruña, como si se tratara de los más violentos delincuentes ${ }^{41}$. Allí mismo, el padre Isla sigue describiendo la ya manifiesta tragedia, en el caso actual de distinta suerte en cuanto al trato humano se refiere, que experimentó el otro Colegio de la diócesis, el de Monterrei:

\begin{abstract}
Muy diferente dicha tuvieron los Padres del Colegio de Monterrey, á quienes tocó un Comisionado que supo hermanar admirablemente los dos dificultosos encargos de su espinosa Comision: ejecutando con la más literal exactitud todo lo que se le mandaba hacer, y permitiendo con la mayor generosidad todo lo que sus facultades le dejaban arbitrio para permitir. El largo y penoso viaje desde Monterrey á La Coruña se hizo con toda la comodidad que podia dar de sí la miseria del país, contribuyendo la tropa con su buen trato y respetuosa atencion á todo lo que era obsequio y alivio de los Padres ${ }^{42}$.
\end{abstract}

A la «Pragmática Sanción» del 2 de abril de 1767, le seguirá otra real cédula del 12 de agosto de 1768, en la que Carlos III, asesorado por su Consejo, manda que se extingan «en todas las Universidades, y Estudios de estos mis Reynos las Cátedras de la Escuela llamada Jesuítica, y que no se usase de los Autores de ella para la enseñanza ${ }^{43}$. Posteriormente, tendría lugar un Consejo Extraordinario, al que habían asistido cinco prelados, y donde se hicieron presentes «otros varios puntos dignos de remedio, relativos a la Doctrina de dichos Regulares expulsos, y otros, para que como Padre de mis Vasallos, y Protector de la Iglesia, tomase las medidas correspondientes, haciendo obedecer mis Reales Ordenes en esta importante materia». Fruto de este Consejo sería la real cédula de Carlos III del 4 de diciembre de 1771, firmada por su secretario Antonio Martínez Salazar ${ }^{44}$.

\footnotetext{
40 Pragmatica Sancion de S. M. en fuerza de Ley para el extrañamiento de estos Reynos á los Regulares de la Compañía, ocupacion de sus Temporalidades, y prohibicion de su restablecimiento en tiempo alguno, con las demás precauciones que expresa. Palacio de El Pardo, 27 de febrero de 1767, título completo del real decreto mencionado. Cfr. Josep María BENíTEZ I RIERA, L'expulsió dels jesuïtes d'Espanya en temps di Carles III, o. c., pp. 46-68.

41 José Francisco DE IsLA, Memorial en nombre de las cuatro provincias de España de la Compañía de Jesús desterradas del Reino á S. M. el Rey Dn. Carlos III, Madrid: Imprenta de Maroto e hijos, 1882, p. 143.

42 Ibíd., p. 143.

43 Real Cédula de Su Majestad, y Sres. del Consejo, por la qual se manda observar y guardar lo declarado sobre la extinción de las catedras, y enseñanza de la escuela jesuítica. Madrid, 12 de agosto de 1768, en AHDOu, Reales Cédulas, leg. 6113.

${ }^{44}$ Real Cédula de Su Majestad, y Sres. del Consejo, por la qual se manda observar y guardar lo declarado en otra de doce de agosto del año pasado de 1768, sobre la extinción de las catedras, y enseñanza de la escuela jesuítica. Madrid, 4 de diciembre de 1771, en ibid., leg. 6113; y en AHN, Consejos, lib. 1486, n. 41.
} 
Y como colofón de esta cadena de desavenencias para los jesuitas, Pedro Rodríguez de Campomanes, se encargaría el 27 de septiembre de 1773 de comunicar al obispo de Ourense, igual que al resto de los prelados españoles, la noticia de la emanación del breve Dominus ac Redemptor del 21 de julio de 1773 que ordenaba la extinción perpetua de la Compañía de Jesús, a la vez que informaba de la resolución del último Consejo para que los Comisionados de Temporalidades respectivos de los dos Colegios de esta diócesis gallega dieran razón puntual de los individuos de la extinguida Orden de la Compañía que existiesen en ella detenidos por enfermedad, vejez u otros motivos, especificando sus nombres, colegios o casas en donde se hallaban en el momento de la expulsión y el convento o reclusión que poseen en la actualidad, «para que se les notifique el Breve de extinción y la Real Cédula expedida para su Cumplimiento» ${ }^{45}$.

\section{INDIVIDUOS EXPULSOS}

Trágica fue la experiencia de los regulares expulsos en Monterrei durante la noche del 1 al 2 de abril de 1767. La villa verinense despertaría la mañana del 2 de abril con la ingrata noticia de haber perdido quizás para siempre la presencia de tan célebre Orden religiosa que durante más de doscientos años había cubierto un papel imprescindible para esta población y contornos como era aquél de la educación y la piedad. El exilio forzado en Italia durante el largo período de cincuenta años, supuso para aquellos jesuitas enfrentarse a un país desconocido, a unas costumbres distintas, a un idioma nuevo y a una supervivencia difícil. En un momento pasaron de ser miembros de una Orden primordial en la educación de los jóvenes españoles y de reconocido prestigio en la vida religiosa de su país, a convertirse en unos extranjeros repudiados por su propio rey, unos seculares desprestigiados tras la extinción de la Compañía por el Papa Clemente XIV ${ }^{46}$.

Estamos ante unos hombres desamparados y de escasos recursos económicos que supieron hacer frente a las adversidades con valentía y sin menoscabo de sus ideas, hasta la restauración del Instituto ignaciano en 1815. Muchos de ellos ya no regresarían a su patria al morir en el destierro; otros, los más jóvenes, les siguieron como novicios al exilio, siendo sujetos muy valorados por

\footnotetext{
45 Carta de Pedro Rodríguez de Campomanes al obispo Francos Arango. Madrid, 27 de septiembre de 1773, y Carta del obispo Francos Arango al rey Carlos III. Orense, 8 de octubre de 1773, en AHDOu, Reales Cédulas, leg. 6113.

${ }^{46}$ Cfr. Inmaculada FernándeZ ArRillaga, El destierro de los jesuitas castellanos (1767-1815), Junta de Castilla y León, 2004.
}

Hispania Sacra, Estudios de Edad Moderna, 58

117, enero-junio 2006, 101-141, ISSN: 0018-215-X 
la comunidad gracias al sacrificio que supuso su fidelidad a la Orden y por ser el único aval de futuro que les quedaba ${ }^{47}$.

Considero que es de justicia traer aquí sus nombres y algunos datos sobre los mismos. De acuerdo con el catálogo publicado en Valladolid en 1767, año de su expulsión, ésta es la lista de los individuos que componen la comunidad del Colegio de Monterrei, 9 sacerdotes y 6 legos, en total 15 miembros. El rectorado estaba vacante. He aquí sus nombres:

Collegium Montirregiense: P.......... Rect.; P. Josephus Delgado, Min.; P. Joannes de Sta. Cruz, Oper. Praef. Spir. Admon. Cons. Catech. ad FF. Conf.; P. Philippus Gutierrez, Oper. Conf.; P. Augustinus Vazquez, Oper. Conf.; P. Franciscus Xaverius Aldao, Conc. Conf. Professores: P. Emmanuel del Barrio, Theol. Mor. Cons. Pref. Sodal. Conf.; P........... Metaphys. Cons. Praef. Sanit. Idem, qui supr. Min.; P. Rochus del Rio, Gram. Praes. Stud. Inf. Sodal. Schol.; P. Raymundus Romero, Gram. Praef. Eccl.; P. Aloysius Sandianes, Gram. Praef. Bibliot. Catech. ad Fam.

FF. Coadiutores: Antonius Rosa, Aedit. Cur. Inf.; Philippus Seco, Ianit.; Josephus Alonso, Ludi-Mag. Cust. Vest. Visit.; Petrus de la Fuente, Proc.; Michael Merino, Coq. Disp. Excit.; Augustinus Frago, Pharmac.

Sacerdotes 9, FF. 6, Socii $15^{48}$.

Esta serie nominal de los componentes de la comunidad de Monterrei se ve complementada por la información que refiere otro importante catálogo de los regulares que residían en las cuatro provincias de Castilla, Toledo, Andalucía y Aragón al tiempo de la intimación del Real Decreto de expulsión, sus destinos en Italia a 1 de enero de 1774, asimismo como la data de fallecimiento y lugar. Tal referencia da una visión bastante aproximada del desenlace de nuestros protagonistas: todos difuntos a excepción de uno que regresaría a España para morir poco después en Madrid, además de un secularizado ${ }^{49}$. He aquí lo que se sabe de cada uno de los quince miembros de la casa de Monterrei:

47 Manuel Luengo, Memorias de un exilio. Diario de la expulsión de los jesuitas de los dominios del Rey de España (1767-1768), ed. Inmaculada FERnÁndeZ ArRILlaGA, Alicante: Publicaciones-Universidad de Alicante, 2002.

48 Catalogus Personarum, et Officiorum Provinciae Castellanae, Societatis Iesu, Vallis-Oleti: apud Thomam á Santander, Typographum Universitatis, ann. 1767, en ARSI, Provinciae Castellanae, Cat. Brev., 1753-1767, n. 30, f. 192r-v.

49 ARSI, Assistentia Hispaniae, n. 147, f. 44. 


\begin{tabular}{|l|l|l|l|}
\hline & SACERDOTES & & \\
\hline 876 & Juan Manuel de Sta. Cruz & S. Juan & Murió en S. Juan, 13 ag. 1792 \\
\hline 877 & José Delgado & Budrio & Murió en Budrio, 3 mayo 1794 \\
\hline 878 & Manuel del Barrio & Cento & Murió en Pezaro, 3 junio 1776 \\
\hline 879 & Felipe Gutierrez & Bolonia & Murió en Bolonia, 1 julio 1767 \\
\hline 880 & Agustín Vázquez & Budrio & Murió en Budrio, 25 febrero 1880 \\
\hline 881 & Francisco Javier Aldao & S. Juan & Murió en S. Juan, 14 febrero 1780 \\
\hline 882 & Roque del Río & Calvi & Murió en Calvi, 20 diciembre 1767 \\
\hline 883 & Ramón Romero & Bolonia & Murió en Bolonia, 20 diciembre 1767 \\
\hline 884 & Luis Sandianes & Budrio & Murió en Madrid, 14 abril 1818 \\
\hline & CoADJuToRES & & \\
\hline 885 & Pedro de la Fuente & Bolonia & Murió en Bolonia, 25 julio 1814 \\
\hline 886 & Agustín del Frago & Bolonia & Murió en Roma en 24 octubre 1808 \\
\hline 887 & José Alonso & Castelfco. & Murió en Bolonia, 24 febrero 1790 \\
\hline 888 & Antonio de la Rosa & Bolonia & Murió en Castelfco. 21 marzo 1789 \\
\hline 889 & Felipe Seco & Pezaro & Murió en Forli, 24 febrero 1776 \\
\hline 890 & Miguel Merino & Bolonia & $\begin{array}{l}\text { Secularizado, 6 junio 1770. } \\
\text { Vivía en 1800 en Ímola. }\end{array}$ \\
\hline & & & \\
\hline
\end{tabular}

\section{APROXIMACIÓN A UN DOCUMENTO INÉDITO}

El documento en cuestión recibe por título Monterrei / Resumen del / Proceso / Sobre la Expuls ${ }^{o n}$. / \& / Regulares. Se trata de un epígrafe que por sí solo resulta bastante clarificador del contenido que recoge. Consta de 44 folios escritos en cursiva currens de la época, plagado de abreviaturas que mantenemos tal cual en la trascripción por ser todas ellas bastante genéricas. Se relata a lo largo de este manuscrito los pormenores de la expulsión de los regulares y el destino que reciben sus temporalidades desde el 2 de abril de 1767, data en que se pone en práctica la Pragmática Sanción del monarca borbón Carlos III, hasta el 24 de agosto del mismo año.

El fiscal de Su Majestad, Pedro Rodríguez Campomanes, confiere a don José García Peñalosa la responsabilidad como Juez comisionado por S. M. para entender en asuntos de temporalidades en dicha villa. Se trata de un personaje

Hispania Sacra, Estudios de Edad Moderna, 58

117, enero-junio 2006, 101-141, ISSN: 0018-215-X 
distinguido por otros títulos como Abogado de los Reales Consejos, Alcade mayor y encargado de la Justicia ordinaria de la Villa, Condado y Estados de Monterrei. Cuenta con la colaboración de aquellos individuos que componen la Junta Municipal de Temporalidades de la que forman parte don José Gómez, regidor de la villa, Juan López y Benito Álvarez. También colaboran don Pedro Barreda Zambrano, abad de la villa y diputado por lo eclesiástico, y don Antonio de la Fuente y Alarcón, abogado de la Real Audiencia, como personero.

De su lectura se deducirá información relevante relacionada con cada uno de los miembros que componen la Comunidad de Monterrei, así como información relativa a los beneficios eclesiásticos y cargas piadosas, viñas y propiedades diversas, rectorado y aposentos varios del Colegio, bodega y farmacia, papeles privados y libros manuscritos, patrimonio artístico y biblioteca. Sin más procedamos a su lectura.

\section{Monterrei / Resumen del / Proceso / Sobre la Expuls ${ }^{o n}$. / \& / Regulares}

AHN, Clero: jesuitas, leg. 807, n. 26.

1767, abril 2-agosto 24

(fol. 1) Ex. ${ }^{\text {mo }}$ Señor.

$\mathrm{D}^{\mathrm{n}}$. Joseph Garcia de Peñalosa Alcalde maior y Justicia hordinaria aprevencion en la Vi. a de Monterrey sus Estados, y Condado, que enttendio con el zelo posible en la espulsión de los PP. Ynmaculados del nombre de Jesus, Aprehensión de sus temporalidades en el Departam..$^{\text {to }}$ de Monterrey y mas anexo al Comettido que se le enttregó para dho. efectto ${ }^{50}$. Haze Presentte a V. E. el Cuerpo de su obra cuio principio fue la enttrega de dho. real Decreto por un rezettor del real tribunal deste R. ${ }^{\text {no }}$ en la mañana del dia dos de Abril destte año, cuia Apertura ejecuttò Sum. ${ }^{\mathrm{d}}$ a presencia de Mathias Perez ess. ${ }^{\text {no }}$ publico rezepttor de dha. Villa de Monterrey y quien dio testimónio de ello, y tubo reservado Sum. ${ }^{\mathrm{d}}$ Ynstruíendose de por si solo del Conttestto de dha. real sanción, y siendo a cosa de las nuebe de la noche del mismo, formò Cartta para el Señor Govern. ${ }^{\text {or }}$ desta Plaza, y attiempo que las Puertas de ella se hallavan Con la Clausura Correspondiente Cuia enttrega se ejecuttò por mano del mismo ess. ${ }^{\text {no }}$ quién debolvio respuesta. Y subsistió en casa de Sum. ${ }^{\mathrm{d}}$ hasta el dia sig. ${ }^{\text {te }}$ que siendo a cosa de las tres de la mañana que se contavan tres del mes de Abril, asociado de el, testigos de excepción y ministros de su audi. ${ }^{a}$ salio Sum. ${ }^{\mathrm{d}}$ enderechura a dho. Co-

50 Historia del Colegio de Monterrey y Sumario de las Escrituras de este Colegio, en AHPOu, Clero: Colegio de Jesuitas de Monterrey, lib. 478; Libro sumario de las escrituras del Colegio de Monterrey (de la historia, origen y progresos de la fundación y de las bulas para la unión de los beneficios), 1586, en ibíd., lib. 479. 
legio halló las puerttas del resguardo de la Plaza francas, y aviendo llegado juntto a las que se nominan (fol. 2) del sol, se enconttró con $\mathrm{D}^{\mathrm{n}}$. Miguel de Leiba Capittan del Rexim. ${ }^{\text {to }}$ de Navarra, con los ofiziales y soldados de su Compañia, y Junttos antes de amanezer en la misma hora se pusieron en Zenttinela en las puerttas y venttanas haciendo zerco a dho. Colegio, multiplicando el resguardo en las Puertas de Correspondiencia, en donde permanecieron sin la menor significazion hasta las quattro de la mañana que un Coadjutor abrio la puertta falsa por donde enttravan y salian los alarifes que se hallavan travaxando en la Obra de la Sachristía, por donde se Yncrepò Sum. ${ }^{\text {, }}$, Capittán, ofiziales, ministros y testigos con asistencia del ess. ${ }^{\text {no }}$ Quienes de Ynproviso se condujeron al Aposentto del P. Manuel de Santta cruz Vize-Rettor que aun se hallava en cama, y puestto en pie con el silencio posible se le hizo saver dho. real decretto

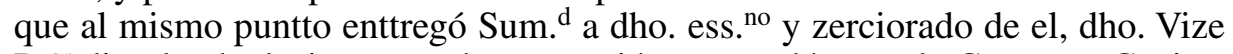
R. ${ }^{\text {or }}$ dixo le obedecia con ttoda venerazión, y mandó tocar la Campana Capitular para que sus subdittos se junttasen y se les zerciorase de su conttestto; executose al punto dha. Juntta y estando en Sala Capittular se les hizo saver dho. Real Decretto que obedecieron y firma. ${ }^{\text {on }}$ con los ttesttigos.

Y de hecho Ynconttinentti Sum. ${ }^{\mathrm{d}}$ practicò (fol. 3) Ygual Convocattoria con los familiares de dho. Colegio Ynttimoles dho. Real Decretto e ympusoles Prezeptto al Cumplim. ${ }^{\text {to }}$ de Clausura.

Sin Ynttermision de tiempo alg'. recojiò Sum. ${ }^{\text {d }}$ las llaves de todos los aposenttos, y con asistencia del Vize-Rettor y Procurador y ess. ${ }^{\text {no }}$ Pasó al reconocim. $^{\text {to }}$ de los archivos, Ynspeccionó Primeram. ${ }^{\text {te }}$ el del Procurador a donde consta averse hallado varios Pap..$^{\text {ls }}$ y un mill quattrocienttos y ochentta $r^{\text {ls }}{ }^{\text {en }}$ platta propios de dho. Colegio ${ }^{51}$.

Pasó Sum. ${ }^{\text {d }}$ al Aposento Rettoral Asoziado de las mismas personas, registró el Archivo del depositto de dho. Colegio, resguardado con dos llaves, no se halló cosa alguna; y en otro Archivo contiguo se hallaron tan solamente varios pap. $^{\text {ls }}$ perttenecienttes a una obra pia titular de Grijoá ${ }^{52}$, Junto con quattromil quarenta y tres rr. ${ }^{\text {ls }}$ y veintte y seis mrs. en moneda dist. ${ }^{\text {ta }}$

51 Tumbo de las rentas, donaciones y permutas y testamentos, hechas a favor del Colegio de la Compañía de Jesús de Monterrey, desde su fundación hasta el año de 1765, en ibíd., lib. 491. Basta una lectura atenta del índice para caer en la cuenta de la importancia que tenía el Colegio de Monterrei en toda esta comarca de Verín. Éste es el encabezamiento: Yndice, de las Scrip ${ }^{\text {ras }}$. de Ventas, Permutas, Donaciones, Testamentos, y otras varias, en favor de este Coll. ${ }^{o}$ de Monte Rey; desde su primitiva Fundación: echo en Jun'. de 1766. Hay documentación referente a las siguientes parroquias: Avedes, Feylas, Flariz, Feces de Avajo, Guillamil y Negueyroa, Monte Rey, Medeyros, Mandin, Mourazos, Quizanes, Tamagos, Tamaguelos, Verin, Villar de Ciervos, Vidiferri, Villarello da Cotta, Villaza.

52 Obra Pía de Grixoá y otras, en AHPOu, Clero: Colegio de Jesuitas de Monterrey, cajas 9957 y 9958. He aquí algunos de sus contenidos: Escritura de fundación de la Obra Pía de Grixoá, Memorial de censos en general, Censos de sacristía, Pleitos, Capilla, Huérfanas, Quiebras, Estudiantes. Reconoció toda esta documentación el comisionado Labora en febrero de 1795.

Hispania Sacra, Estudios de Edad Moderna, 58

117, enero-junio 2006, 101-141, ISSN: 0018-215-X 
Pasó Su M. ${ }^{\text {d }}$ igualm. ${ }^{\text {te }}$ sin divertirse en otra cosa al Aposento de el Lector de Moral, asoziado de las Personas menzionadas, y en dos Cajonzitos, se encontraron en oro, Plata, y vellón, dos mil trescientos setenta y un $\mathrm{r}^{\mathrm{s}}$ y nueve mrs., cuio Deposito, dijeron los P.P. era peculiar de la Congregaz. ${ }^{\mathrm{n}}$ de S. ${ }^{\mathrm{n}}$ Joseph, establezida para Moralistas, y Philosophos; recogió Sum. ${ }^{\mathrm{d}}$ el Dinero, y cerró el Aposento.

Con la misma solemnidad, y celo continuó Sum. ${ }^{\text {d }}$ el rexistro haziendo transito al Aposento (fol. 4) Titular deel P. Prefecto, y en un Cajón encontró treinta r. $^{\mathrm{s}}$ en vellon, que dijeron ser de la Congregazión de nuestra Señora, erigida por Dotazión de algunos Grammaticos; recogiolo Sumd., y cerró dho. Aposento.

Y a continuaz. ${ }^{\mathrm{n}}$ de ello, se increpó en la Botica de dho. Coll. ${ }^{\mathrm{g}} \mathrm{y}$ en un Caxon de ella, a pres. ${ }^{\mathrm{a}}$ de los circunstantes, se numeraron veinte y nueve $\mathrm{r}^{\mathrm{s}} \mathrm{y}$ veinte $\mathrm{y}$ dos mrs. en Plata, y v. ${ }^{\mathrm{n}}$ con lo q $\mathrm{q}^{\mathrm{e}}$. se cerró dha. Botica.

En medio de haver Sumd. con la misma solemnidad, acompañamiento, y exactitud, registrado muy por menudo todos los demas Aposentos, no encontró

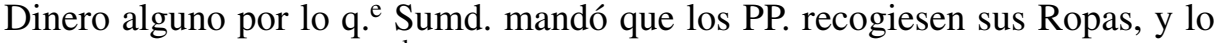
mas q. ${ }^{\text {e }}$ les facultaba la R. ${ }^{1}$ Ynstrucz. ${ }^{n}$ para su Diario servicio, y pronta marcha, y extrahido lo referido de los Aposentos, tomó Sumd. las llaves, hizo custodiar lo restante y con la misma formalidad, juntando todas las Alhajas de Plata, diputadas para el ministerio de la Yglesia, las increpó en una Lazena, q. ${ }^{\mathrm{e}}$ se hallaba en el Aposento Rectoral interin no llegaba el tiempo de su devido requento ${ }^{53}$.

En el mismo día, Sumd. con ass. ${ }^{a}$ del Vize-Rector, Procur. ${ }^{\mathrm{r}}$, mas Personas expresadas, y ess. ${ }^{\text {no }}$ se pasó a la Biblioteca en la q. ${ }^{\mathrm{e}}$ no encontró mas que diferentes Libros, q. ${ }^{\mathrm{e}}$ dijeron ser propios de el Coll. ${ }^{\mathrm{g}}$ los q. ${ }^{\mathrm{e}}$ dejó Sumd. inclusos haziendose caja de la llave ${ }^{54}$.

(fol. 5) En el mismo dia, Considerando Sum. ${ }^{\mathrm{d}}$ que desp. ${ }^{\mathrm{s}}$ de finalizado lo precedentte, Ynstava la obligacion de su encargo el surttimiento y subrrogazion de Maestros incontinenti constituió p. ${ }^{\mathrm{r}}$ tales en todas Cathedras personas virtuosas, y las mas dignas para el ministerio.

De executado lo referido, conociendo Sum. ${ }^{\mathrm{d}}$ las bastas ocurrencias que significa el negocio que $\mathrm{p}^{\mathrm{r}}$ si solo serán inexpeditas, puso por Adjunto a d. ${ }^{\mathrm{n}}$ Juan Garzia de Peñalosa, quien obedezió a pres. ${ }^{\mathrm{a}}$ de un ess. ${ }^{\text {no }}$

Considerando Sumd. finalizado el dia, puso con la formalidad devida la Tro-

53 Inventario de toda la Hacienda del Colegio de Monterrey, 1717, en ibíd., lib. 492.

${ }^{54}$ Real resolucion de S. M. para / que se enttreguen a la Real Universidad de Sant. ${ }^{\circ}$ / los Libros que fueron de Regulares expatriados / de estta Villa, a excepcion de los de Letras huma- / nas Geografia, Mathemattica Philottage y nauti- / ca = / Entrego de ello en su virtud / A Sus Mrdes. el Padre Mro. Fr. Domingo Martz. I y el Dr. Dn. Andres Viz ${ }^{t e}$. Mosquera Apoderados de / referida Universidad, en ibíd., caja 9950. 
pa en las Puertas, y Ventanas de el Coll. ${ }^{\circ}$ encargando al Capitan les constriñiese al mas exacto resguardo.

Por la misma causa de la prosimaz. ${ }^{n}$ de la Noche, considerando Sumd. ser incapaz la Pieza Capitular en donde se hallan los PP. de recivirlos p. ${ }^{\text {a el descan- }}$ so de aquella noche, por lo reduzido de ellas mandó se pusiesen camas también en otros dos Quartos immediatos a donde se acomodaron, haviendosele hecho saver se abstuviesen de toda comunicazion, y de salir de dhos. Quartos.

En el día quatro a la mañana, mandó Sumd. apres. ${ }^{\text {a }}$ de el ess. ${ }^{\text {no }}$ para maior resguardo de lo q. ${ }^{\mathrm{e}}$ se halla en dho. Coll. ${ }^{\mathrm{g}}$ cerrar una Puerta falsa, $\mathrm{p} .{ }^{\mathrm{r}}$ la que entraban los materiales para la fabrica de la nueba Sachristía, y resguardar porzión de Madera, q. ${ }^{\mathrm{e}}$ se hallaba fuera.

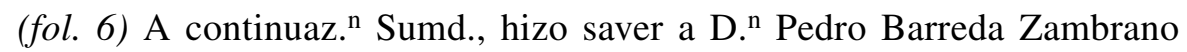
Abad de Monterrey, dijese Misa secreta en la Yglesia de el Coll..$^{\mathrm{g}}$, consumiese las sagradas Reliquias, y purificase los Sagrados Vasos, lo que se executó.

Sin pasar a otra cosa considerando se llegaban las Veinte y quatro Horas q. ${ }^{\text {e }}$ permitia la R. ${ }^{l}$ Ynstrucz. ${ }^{\mathrm{n}}$ a los $\mathrm{P} .{ }^{\mathrm{s}}$ de mansion en el Coll. ${ }^{\mathrm{g}}$ a pres. ${ }^{\mathrm{a}}$ de varios sugetos, entregó Sumd. cinco mil R. ${ }^{\mathrm{s}}$ de oro al Then. ${ }^{\text {te }}$ D. ${ }^{\mathrm{n}}$ Pedro Orlandiz para los gastos de el transporte de los $\mathrm{P}^{\mathrm{s}}$ a la Coruña; y al mismo tiempo condujo al Convento de S. ${ }^{\mathrm{n}}$ Fran. ${ }^{\text {co }}$ de la Villa de Monterrey treinta y seis Carneros de el Coll.g para que el Padre Guardian los mandase apazentar con los suios.

De executado lo sobredho., Sumd. en el mismo dia entregó a d. ${ }^{n}$ Miguel de Leyba, Capitan de el Reximiento de Navarra todos los PP. a excepz. ${ }^{\mathrm{n}}$ de el P. Procurador que quedó p. $^{\mathrm{r}}$ entonzes en este Coll. ${ }^{\mathrm{g}}$; y juntamente para su descanso ocho colchones; y assi mismo dos mulas, y una Aca propias de el Coll. ${ }^{\mathrm{g}}$ para que les conduzcan a la Coruña.

En el mismo dia, y luego al punto, que los PP. con el resguardo de la Tropa emprehendieron la marcha para la Coruña, Sumd. apres. ${ }^{\text {a }}$ deel Ess. ${ }^{\text {no }}$ considerando desauxiliado dho. Coll. ${ }^{\mathrm{g}}$ por un Ministro pasó a pedir soldados al Govern. ${ }^{\text {or }}$ de la (fol. 7) Plaza de Monterrey, i incontinenti aquel hizo regreso con un Sargento, y seis Soldados, los q. e destinó Sumd. a los suios mas sospechosos, y de executado con ass. ${ }^{a}$ de el P. Procur. ${ }^{\text {or }}$, Abad de Monterrey, y Ess. ${ }^{\text {no }}$ pasó al Ymbentario de las Alhajas que se consideran de el ministerio de la Sachristia que tenia Sumd. inclusas en el Aposento Rectoral; y asociado de los sres. dhos., hizo sin intermision de tpo. en otro negocio, el de los

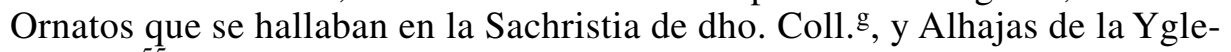
sia de $\mathrm{el}^{55}$.

En dho. dia considerando Sumd. el Capitulo veinte y dos de su R. ${ }^{1}$ Yns-

\footnotetext{
55 Censos, pleitos y otras escrituras de los bienes de la Sacristía de este Colegio, 1588-1710, en ibíd., lib. 493.
}

Hispania Sacra, Estudios de Edad Moderna, 58

117, enero-junio 2006, 101-141, ISSN: 0018-215-X 
trucz. ${ }^{\mathrm{n}}$ para que los Procur. ${ }^{\mathrm{es}}$ queden en el Pais, se hizo entrega al P. Guardian de S. ${ }^{\mathrm{n}}$ Fran. ${ }^{\mathrm{co}}$ de el P. Procurador amonestandole su resguardo.

En el dia cinco, solizitando Sumd. el cumplimiento de dha. Ynstrcz. ${ }^{\text {on }}$ asociado de varios sugetos distinguidos, y Ess. ${ }^{\text {no }}$, continuó el Ymbentario, y se pasó al Quarto de Dispensa, y de calculada lo que se hallaba alli incluso, continuó al Refectorio, haziendo igual requento, y de alli con la misma solennidad, y sin intermision de otro negocio, se pasó a la Cocina, y despues a la Procurazion, suspendiendo en el dia seis el finalizarlo por ser preziso al cumplim. ${ }^{\text {to }}$ de su Real Comision algunas providenzias, $\mathrm{q} .{ }^{\mathrm{e}} \mathrm{se}(\mathrm{fol} .8)$ tomaron, y recobro de algunos maravedis ${ }^{56}$.

En el dia siete, Sumd. con asistencia de el P. Procur. ${ }^{\text {or }}$ testigos de excepzion, y dho. Ess. ${ }^{\text {no }}$ finalizó el requento del Omenaje del Quarto de Procurazion, q. ${ }^{\mathrm{e}}$ en el se hallaba incluso; y con la misma asistenzia, y sin ninguna intermision, se pasó al quarto de Roperia recontando mui por menor todo lo existente en el, siguiendo, asociado de las mismas personas, al Quarto de el numero segundo, q. ${ }^{\text {e }}$ havitaba el P. Manuel del Barrio Maestro de Moral, e hizo requento con toda vigilanzia del Omenaje alli existente, y algunos Libros, que suspendió por ser Noche.

En el dia ocho, teniendo Sumd. presente que en las Granjas de Quizanes, y Villaza de este Coll.g existen las Basijas de vino, y porzion de este, y mas Omenaje, se pasó a la de dha. Quizanes ${ }^{57}$ asociado de dho. ess. ${ }^{\text {no }}$, el P. Procur. ${ }^{\text {or }} \mathrm{d} .{ }^{\mathrm{n}}$ Fran. ${ }^{\text {co }}$ Rodriguez Abad de aquella feligresia, y otras pers. ${ }^{\text {as }}$ e hizo Requento de todo el Omenaje, Granos, y Vino, q. ${ }^{\mathrm{e}}$ se halló, finalizando esta Operaz. ${ }^{\mathrm{n}}$ con toda solennidad ${ }^{58}$.

En el dia nueve, se pasó Sumd. con ass..$^{\text {a }}$ de dho. Procur. ${ }^{\text {or }}$, ess. ${ }^{\text {no }}$ y otros testigos a la Granja de el Lugar de Villaza, e hizo requento en la misma forma del Omenaje, Granos, y (fol. 9) Vino incluso en dha. Granja, y de finalizado en el mismo dia, se pasó Sumd. al Requento de lo existente en la casa de Verin de dho. Coll. ${ }^{\mathrm{g}}$ asociado de el mismo Procur. ${ }^{\text {or }}$ Ess. ${ }^{\text {no }}$ y testigos, q. ${ }^{\mathrm{e}}$ de el consta, y despues de finalizado por la proximidad de Noche con ass. ${ }^{a}$ de dho. Ess. ${ }^{\text {no }}$, entregó dho. Procur. ${ }^{\mathrm{r}}$ al P. Guardian de el Convento de S. ${ }^{\mathrm{n}}$ Fran. ${ }^{\text {co }}$

\footnotetext{
56 Abundante información al respecto, en Temporalidades de los ex. Jesuitas. Año de 1835 / Ynventario $\mathrm{Num} .{ }^{\circ} 3 .^{\circ}$ de las fincas rusticas y urbanas con espresion de aquien se hallan arrendadas, en que precio y por cuanto tiempo lo que adeudan los colonos y arrendatarios, donde radican, y las cargas de Justicias así Civiles como Eclesiasticas, en ibíd., caja 9950; Temporalidades, en ibíd., caja 9959; Temporalidades. Cuentas del administrador de Temporalidades de Monterrey, 1768-1780, en ibíd., caja 9960; Temporalidades. Cuentas del administrador de Temporalidades de Monterrey, 1780 1800, en ibíd., caja 9961.

57 Sobre subasta de las fincas Diestrales de Quizanes. Monterrey, 1793, en ibíd., caja 9959.

58 Tumbo de las rentas, donaciones y permutas y testamentos, hechas a favor del Colegio de la Compañía de Jesús de Monterrey, desde su fundación hasta el año de 1765, en ibíd., lib. 491, ff. 161 y ss. habla de los foros que regían la administración de estos terrenos, sobre todo las viñas.
} 
En el dia Diez, pasó Sumd.; a Ygnazio Bouzán; Maestro de Canteria; los Salarios, q. ${ }^{\mathrm{e}}$ se les devian de vengados en la Semana de la Expulsion p. ${ }^{\mathrm{r}}$ si, y Oficiales en la Obra de Sachristia.

En el mismo dia, teniendo presente Sumd., q. ${ }^{\text {e }}$ en los lugares de Mandin ${ }^{59}$, y Mourazos $^{60}$, tiene el Coll. ${ }^{\circ}$ casas de Panera, se pasó a ellos con ass. ${ }^{\text {a de el Pro- }}$ cur. $^{\mathrm{r}}$ Ess. $^{\text {no }}$ y test. ${ }^{\text {os }}$, haziendo requento de lo existente en ellas, y de restituido en el mismo a este Coll. ${ }^{\circ}$ con la proximidad de la Noche, hizo igual entrega de dho. Procur. ${ }^{\text {or }}$

En el dia Onze, acompañado Sumd. de dho. Procurador, y testigos de excepz. ${ }^{\text {on }}$, prosiguio en el requento de los Libros, existentes en el Aposento de el P. Manuel del Barrio, Maestro de Moral.

En el refer. Dia, despues de finalizado dho. requento, dio prinzipio con la misma Ass. ${ }^{\text {a }}$ (fol. 10) al Ymbentario de los Ynstrum. ${ }^{\text {os }}$ y mas Pap. ${ }^{\mathrm{s}}$ existentes en el Archivo del Quarto de Procuraz. ${ }^{\mathrm{n}}$ correspond. ${ }^{\text {tes }}$, a los vienes, y mas rentas de este Coll. ${ }^{\circ}$, y sus curatos, en cuio requento continuo asta la noche de el dia quinze del zitado mes de Abril ${ }^{61}$.

En el dia diez y seis del mismo, por orden, q. ${ }^{\text {e }}$ Sumd. obtubo del S. ${ }^{\text {r Capitan }}$ General de este Reino, p. $^{\text {a }}$ que sin perdida de tiempo remitiese a la ciudad de la Coruña la Ropa de cama, y mesa, y mas utensilios de cocina que se contemplasen prezisos para el servicio de los Religiosos, en vista del qual, suspendió el Ymbentario del citado Archivo, y con ass. ${ }^{\text {a }}$ de dho. Procurador, Ess. ${ }^{\text {no; }}$ y testigos hizo Ymbentario de todas las ropas, que se hallaban por recontar en los Aposentos de dho. Coll. ${ }^{\mathrm{g}}$, y de evaquado por la proximidad de la noche hizo entrega de dho. Procur. ${ }^{\text {or }}$ en el Convento de S. ${ }^{n}$ Fran. ${ }^{\text {co }}$

En el dia diez y siete, teniendo Sumd. pres ${ }^{\text {tes }}$ la referida Orden para su pronto expediente, y remesa de lo mandado a dha. ziud. ${ }^{\mathrm{d}}$, nombra ${ }^{\mathrm{r}}{ }^{\mathrm{r}}$ conductor a D. ${ }^{\mathrm{n}}$ Mauro de Vila, e hizo venir de las Granjas las Ropas y mas conduzente para incluir en dha. remesa.

En el mismo dia, Sumd. asistido de dho. (fol. 11) Procur. ${ }^{\text {or }}$, ess ${ }^{\text {no }}$, y test. ${ }^{\text {os }}$, mando hazer fardos de dhas. Ropas, e hizo entrega de ellas, y mas Omenaje $\mathrm{q}^{\mathrm{e}}$ considero ser preziso p. ${ }^{\text {a }}$ el servizio de los Religiosos, al Conductor nombrado, a quien igualm. ${ }^{\mathrm{e}} \mathrm{p}^{\mathrm{a}}$ los gastos del Carruage en el transporte en el dia diez y ocho, le entregó Pasaporte, y un mil $\mathrm{R}^{\mathrm{s}}$ de $\mathrm{v}^{\mathrm{n}}$.

En dho. dia diez y ocho, mandó Sumd. formar, y se formó testim. ${ }^{\circ}$ de todo lo entregado al Conductor y remitió por el correo a dho. S. ${ }^{\mathrm{r}}$ Capitan General.

\footnotetext{
59 Venta de la Casa y tulla de Mandín por Nuño González y consorte, en ibíd., ff. 212r-213r.

${ }^{60}$ Venta de Gaspar Pardo y su mujer de una Casa, que es donde está la tulla, en ibíd., ff. 225r228r. Ejemplo de otras adquisiciones es el siguiente: Real carta Ejecutoria y autos contra los poseedores del casal de Pedro de Vilela y Costanza Fernández, en Mourazos, 1718, en ibíd., lib. 488.

61 Libro de concordias y curatos, 1579-1766, en ibíd., lib. 495.
} 
En el mismo dia, atendiendo Sumd., a que dho. Coll. ${ }^{g}$ tiene Bodega subterranea dentro de el con la misma ass. ${ }^{a}$ se introdujo en ella, y se contó lo q. ${ }^{\mathrm{e}}$ se halló incluso, y por resultar tener porzion de vino lo entregó por medida al Casero de Verin para su venta.

En el dia diez y nueve del zitado Mes, Sumd. con ass. ${ }^{a}$ de dho. Procur. ${ }^{\text {or, }}$ ess. $^{\text {no; }}$ y testigos, prosiguió en el requento de los Ynstrum. ${ }^{\text {os }}$ y Papeles de el Archivo de Procurazion que ha finalizado en el dia veinte del mismo Mes ${ }^{62}$.

En el referido dia con dha. ass. ${ }^{\text {a }}$ hizo Sumd. Ymbentario de los Libros de quenta, y razon, y otros Papeles, y Cartas, que se hallaron al tiempo de la expulsion (fol. 12) en el Quarto referido de Procurazion y de finalizado en el mismo dia mandó Sumd. hazer la trashiega de vino existente en las Granjas de Quizanes $^{63}$ y Villaza ${ }^{64}$ por ser tpo. en q. ${ }^{\mathrm{e}}$ lo hazen los demas cosecheros, comisionado para ello a D. ${ }^{\mathrm{n}}$ Juan Garzia de Peñalosa por ser de su maior satisfacz. ${ }^{\mathrm{n}}$ p. ${ }^{\mathrm{a}} \mathrm{q} .{ }^{\mathrm{e}}$ este con ass. ${ }^{\mathrm{a}}$, y p. $^{\mathrm{r}}$ medio de Hombres practicos en dho. oficio, procediese a dha. ocupazion; y q..$^{\mathrm{e}}$ recoja las Borras q. ${ }^{\mathrm{e}}$ queden del vino para hazer Agua-Ardiente para el Despacho de la Botica de este Coll. ${ }^{\circ}$, finalizando dho. mandato en el dia veinte y uno.

En el mismo dia veinte y uno, se presentó a Sum. ${ }^{\mathrm{d}}$ testim. ${ }^{\circ}$, por el que consta haverse entregado de horden de dho. S. ${ }^{\mathrm{r}}$ Capitan general a dos Mozos, q. ${ }^{\mathrm{e}}$ havian ido a dha. ciudad con los Regulares, y Mulas conduzidas de este Coll. ${ }^{\circ}$, zien r. ${ }^{\mathrm{s}}$ de v. ${ }^{\mathrm{n}}$ para suplir los Gastos hechos con ellos, y manutenzion de aquellas en la misma ziudad, y restituirse a esta Villa acompañando a dho. testim. ${ }^{\circ}$ la quenta dada p. ${ }^{\mathrm{r}}$ dhos. Mozos de la expresada Cant. ${ }^{\mathrm{d}}$

En dho. dia veinte y uno, por la ocurrencia de la noche hizo Sumd. entrega de el Procur. ${ }^{\text {or }}$ en dho. convento se S. ${ }^{\mathrm{n}}$ Fran. ${ }^{\text {co }}$

(fol. 13) En el dia veinte y dos de dho. mes de Abril deseando Sumd. el azierto en su r. ${ }^{l}$ Comision, y savedor de que dho. Coll. ${ }^{\circ}$ tiene una casa de Panera en el lugar de Medeiros ${ }^{65}$ y otra en el de Nigueiroá ${ }^{66}$; y que no podia salir de

\footnotetext{
62 Ynventario de los papeles del Colegio de la exting. ${ }^{a}$ Comp. ${ }^{a}$ de Jesus / de la V. ${ }^{a}$ de Monterrey hecho por D. Vent. ${ }^{a}$ Román, en ibíd., caja 9950.

${ }^{63}$ Cfr. AHPOu, Clero: Colegio de Jesuitas de Monterrey, lib. 491, ff. 260r-267v., que recoge varias escrituras.

${ }^{64}$ Ibíd., lib. 491, ff. 359r-401v, donde constan diversas ventas de casas al Colegio de la Compañía.

65 Va incluida en la Donación de las casas adquiridas por el abad de Medeiros, el bachiller Francisco de Lerma, a favor de este Colegio para reparos de las escuelas y Colegio, en ibíd., lib. 491, ff. 164r-165v. Además se recoge el testimonio de este bachiller para ser recibido en la Compañía de Jesús, en ibíd., ff. 166r-168r. Sobre la relación de esta parroquia con el Colegio de Monterrei, cfr. Tumbo viejo de Medeiros, 1513-1584, en ibíd., lib. 480; Tumbo de la iglesia de Santa María de Medeiros, 15641634, en ibíd., lib. 481.

66 «Venta de un ferreiro y su mujer, de un almude de linar, donde oy es tulla», en AHPOu, Clero: Colegio de Jesuitas de Monterrey, lib. 491, ff. 70r-74r.
} 
este Coll. ${ }^{\circ}$ por las continuas ocupaziones en el expediente de su cometido; y para que este no se atrasase, comisionó para el requento de lo incluso en dhas. casas a d ${ }^{\mathrm{n}}$ Juan Garzia de Peñalosa Persona de su satisfaczion, para que lo executase de fenezida la trashiega de vino en que se hallaba por ante Testigos, y hecho viniese a dar razon.

Por carta orden de el S. ${ }^{\mathrm{r}}$ Capitan General de este R. ${ }^{\text {no }}$ fha. onze de Abril, se previene a Sumd., que viendo nezesario el uso de Botica para surtir los Pueblos pusiese persona de confianza, e inteligenzia que la administre ${ }^{67}$.

En el mismo dia veinte y dos; teniendo Sumd. presente lo mandado por dha. orden, hizo comparezer a d. ${ }^{n}$ Ysidro Fidalgo Medico Titular, d. ${ }^{\mathrm{n}}$ Vizente Lorenzo Boticario, y d. ${ }^{n}$ Santiago Guerra Manzebo que fue en la Botica de este Coll. ${ }^{\mathrm{o}}$ y con su ass. ${ }^{\mathrm{a}}$; la de dho. Procr. ${ }^{\text {or }}$ ess. $^{\text {no }}$ y Ministro, dió prinzipio al Ymbentario de las Medizinas, y Drgas de dha. Botica, que suspendió en el dia veinte y tres, por haver recivido la noche de el Veinte y dos la r. ${ }^{1}$ Pragmatica Sanccion con r. ${ }^{1}$ Provision para que se hiziese saver a dho. Procur. ${ }^{\text {or }}$ el contenido de dha. r. ${ }^{1}$ Pragmatica, y de dha. notificaz. ${ }^{n}$ se remitiese (fol. 14) Testim. ${ }^{\circ}$ authentico al R. ${ }^{l}$ Consejo, lo q. ${ }^{\text {e }}$ se dirigió a Sumd. por carta de Catorze de Abril firmada de Ygareda.

En dho. dia veinte y tres se hizo saver dha. r. ${ }^{1}$ Pragmatica Sanccion al P. Pedro de la Fuente Procur. ${ }^{\mathrm{r}}$ quien enterado de su contenido, la obedezió.

En el dia veinte y quatro de el mismo Mes, se formó testim. ${ }^{\circ}$ de la deligenzia practicada con dho. Procur. ${ }^{\mathrm{r}}$ y se remitió al r. ${ }^{1}$ Consejo por el Correo ordinario.

En el mismo dia, se prosiguió con la zit. ${ }^{a}$ ass. ${ }^{a}$ al requento de los Medicamentos de dha. Botica.

En el dia veinte y cinco de dho. mes, deseando Sumd. la conservazion de vino existente en las Granjas, mandó se hiziese saver a d. ${ }^{\mathrm{n}}$ Juan Garzia de Peñalosa que se hallaba en su trashiega, nombrase dos hombres expertos en el conocimiento de este Genero, para que fuesen a su reconocimiento a fin de saver $\mathrm{p}^{\mathrm{r}}$ sus declaraziones si se podia guardar sin peligro para tiempo que tuviese maior valor, o requeria pronta venta.

En el mismo dia, se proseguió en el Ymbentar. ${ }^{\circ}$ de dha. Botica y sin intermision de otras diligencias, mas que solamente la entrega diaria de el Procur. ${ }^{r}$ en S. ${ }^{n}$ Franc. ${ }^{\text {co }}$ se continuó en el asta el dia primero de el mes de Maio en que se concluió.

En el dia veinte y dos, digo dos de dho. mes atendiendo Sumd. a lo mandado por el S. ${ }^{\mathrm{r}}$ Capitan Gral. de este (fol. 15) R. ${ }^{\text {no }}$, proveió, q. ${ }^{\mathrm{e}}$ dho. Medico, declara-

67 Interesante seguir su evolución en Certificaciones 1788-1796, del escribano de Monterrei y del de Verín, sobre aplicación de la Iglesia y Colegio de los Jesuitas de Monterrei, y sobre las deudas que han quedado de la Botica del mismo, AHN, Clero: jesuitas, leg. 181, nn. 2-3.

Hispania Sacra, Estudios de Edad Moderna, 58

117, enero-junio 2006, 101-141, ISSN: 0018-215-X 
se, como de la facultad la persona, que tuviese por mas habil, y de confianza para hazer la entrega de dha. Botica.

En el mismo dia dos, se hizo saver al zitado Medico, quien por su declaracion, señalo por habil, y sufiziente, y de toda confianza para el ministerio de Boticario a d. ${ }^{\mathrm{n}}$ Santiago Guerra, expresando los motivos que tenia para nombrarle.

En el zitado dia, teniendo Sumd. presente lo expuesto por dho. Medico, acompañado de este, Procr. ${ }^{r}$ y test. ${ }^{\text {os }}{ }^{\text {de excepz. }}{ }^{n}$, le hizo entrega por ante el ess. $^{\text {no }}$ de toda la Medizina, Libros, y Omenaje, q. ${ }^{\mathrm{e}}$ se halla en dha. Botica, y consta de el Ymbentar. ${ }^{\circ}$, haziendolo assi mismo de las Medidas de plata, y de otros Metales, llaves de sus puertas, Casa de destilar, y Jardines, entregandose a dho. nombrado de todo ello, y ofreziendo dar quenta de su producto.

En el mismo dia, mandó Sum. ${ }^{\text {d }}$ q. ${ }^{\text {e }}$ dho. Medico, y Boticario, respecto la satisfacz. ${ }^{\mathrm{n}}$ que de ellos tenia, tasasen las rezetas, $\mathrm{q} .{ }^{\mathrm{e}}$ se hallaban existentes, y hecho viniesen a dar razon, para su ymbentar. ${ }^{\circ}$ formal, y perzepz. ${ }^{\mathrm{n}}$ de su Ymporte; y q. ${ }^{\mathrm{e}}$ para el pronto expediente de su r. ${ }^{1}$ cometido interin se executaba dha. Tasa, se pasase al Ymbentario de los Papeles correspond. ${ }^{\text {es }}$ a la obra pia titular de Alonso Rodriguez.

Yncontinenti se dió principio p. ${ }^{r}$ Sumd. con ass. ${ }^{\mathrm{a}}$ de dho. Ess. ${ }^{\text {no }}$ y testigos al nominado Ymventario de los Pap. ${ }^{\text {es }}$ de dha. obra pia.

(fol. 16) En el dia tres, atendiendo Sumd. a haverse pronto la Botica de este Coll. ${ }^{\circ}$ de Boticario para su Despacho, mandó formar ocho cartas mismas para q. ${ }^{\text {e }}$ las Justizias de la circunferenzia, y sus Montañas, las publicasen a los naturales de sus respectivos Domizilios, lo q. e se executó.

Y en el mismo dia prosiguió Sumd. en el Ymbent. ${ }^{\circ}$ de la zitada obra pia de Alonso Rodriguez, y de finalizada en el mismo con dha. ass. ${ }^{a}$ dio prinzipio al requento de los Papeles concernientes a la q. ${ }^{\mathrm{e}}$ se intitula de Maria Garzia cuios Documentos, pretende el Convento de la Merced de la Villa de Verín, se le entreguen por los motivos, q. ${ }^{\mathrm{e}}$ expresan en su pedimento ${ }^{68}$.

En el dia quatro de dho. mes de Maio, se dio principio a las quentas del Procur. $^{\mathrm{r}}$ que era de dho. Coll. ${ }^{\mathrm{o}}$, y de finalizadas las correspond. ${ }^{\mathrm{s}}$ al Coll. ${ }^{\mathrm{o}}$ sin intermision alguna se le tomaron los que corresponden a la obra pia titular de Maria Garzia; y de concluida esta a la misma continuaz. ${ }^{\mathrm{n}}$ se dio prinzipio a la quenta de las rentas de Sachristia de dho. Coll. ${ }^{\circ}$ digo de la obra pia, que se nombra de Alonso Rodriguez de la q. ${ }^{\mathrm{e}}$ era Patrono el Rector, y Adm. ${ }^{\text {or }}$ dho. Procur. ${ }^{\mathrm{r}}$, y eva-

68 Libro 2. ${ }^{\circ}$ de foros y censos otorgados a favor del Br. Juan Roberto y de su mujer María García, vecinos de Verín y pertenecientes a la Obra Pía fundada por los referidos, de la que era patrono el P. Rector del Colegio de Monterrey, 1614-1626, en AHPOu, Clero: Colegio de Jesuitas de Monterrey, lib. 486. 
quado el cargo, y data de esta, se continuó en la misma forma en la quenta correspond. ${ }^{\mathrm{e}}$ a la Sachristia de dho. Coll. ${ }^{\circ}$ : cuias quentas, se finalizaron en el dia doze de dho. Mes de Maio.

En el dia treze, comparez. ${ }^{\text {on }}$ Antonio Rodriguez, y Fran. ${ }^{\text {co }}$ Tizón, declarando el estado de los vinos, que tenia dho. Coll. ${ }^{\circ}$ en virtud de haverlos nombrado para este efecto d. ${ }^{\mathrm{n}}$ Juan Garzia de Peñalosa, y por resultar de sus declaraz. ${ }^{\text {es }}$ (fol. 17) ser dhos. vinos de infima calidad, y mal acondizionados mandó Sumd. a dho. D. ${ }^{\mathrm{n}}$ Juan los vendiese, y benefiziase para su pronto desp'., e hiziese conduzir las Borras para la formazion de Agua-ardiente, y hecho con los hombres nezesarios hiziese la caba de viñas, llevando en todo la quenta; y razon correspond. ${ }^{\mathrm{e}}$

En el zitado dia, comparez. ${ }^{\text {on }}$ ante Sumd., y ess. ${ }^{\text {no }}$ dhos. Medico, Boticario, declarando haver hecho la tasa del rezetario.

En el mismo dia, se mandó q. ${ }^{\mathrm{e}}$ un Ministro compareziese al Conductor de las ropas, y omenaje para tomarle quenta de la cant. ${ }^{\mathrm{d}}$ entregada para su transporte.

En dho. dia, se pagó a Juan Foubelo criado q. ${ }^{\text {e }}$ fue de Sachristia los salarios, q. $^{\text {e }}$ le devia el Coll. ${ }^{\circ}$; siguiendo a esta diligenzia la petizion presentada $p .^{r}$ el Commendador de la Merced, pidiendo, se le pagasen un mil maravedis que le devia el Coll. ${ }^{\circ}$ como Patrono de la obra pia de Maria Garzia; y que assi mismo se le entregasen los Ynstrumentos a ella correspond. ${ }^{\text {es}}$ : en cuia vista m. ${ }^{\text {do }}$ Sum. ${ }^{\mathrm{d}}$ acudiesen a donde tocaba.

En el zitado dia treze, parezió ante Sumd., y ess. ${ }^{\text {no }}$ d. ${ }^{n}$ Juan Garzia de Peñalosa, y declaró haver hecho muy por menor el requento de lo incluso en las Casas, q. ${ }^{\mathrm{e}}$ tiene el Coll. ${ }^{\mathrm{e}}$ en Medeyros, y Nigueiroá, lo q..$^{\mathrm{e}}$ ha practicado $\mathrm{p} .^{\mathrm{r}}$ ante sufiziente numero de Testigos.

(fol. 18) En dho. dia treze, compareció el conductor de las Ropas, y omenaje remitido a la Ciudad de la Coruña, y entregó el rezivo de la entrega de uno, y otro, y dió la quenta de los un mil R. ${ }^{\mathrm{s}}$ que Sumd. le entregó para gastos en dho. transporte.

En el zitado dia, se pagaron a d. ${ }^{\mathrm{n}}$ Mauro Vila sesenta y seis R. ${ }^{\mathrm{s}}$ que havia dado al Procur. ${ }^{\mathrm{r}}$ unos dias antes de la expulsion para que se los librase en la Cor. ${ }^{\mathrm{a}}$

En el mismo dia, atendiendo Sum. ${ }^{\mathrm{d}}$ a haver concurrido las Borras del vino, señaló persona, para q. ${ }^{\mathrm{e}}$ de ellas hiziese Agua-ardiente.

En el zitado dia treze, mandó Sumd. para el pronto expediente de su comision hazer Ymbentario de las rezetas, que se hallaban tasadas en la Botica de dho. Coll. ${ }^{\mathrm{o}}$ y hecho q. ${ }^{\mathrm{e}}$ el Procur. ${ }^{\mathrm{r}}$ diese la quenta de ella.

En el dia catorze de dho. Mes, Sumd. asistido del Procur. ${ }^{\mathrm{r}}$, ess. ${ }^{\text {no }}$, y testigos, 
dió prinzipio al Ymbentario de las rezetas, que se hallaban en un Armario con diez y siete navetas del q. ${ }^{\text {e }}$ Sumd. tenia la llave, poniendo los Lugares donde resultaban los Deudores p. ${ }^{\mathrm{r}}$ Abezedario, y de finalizado el requento de ellas, y sus Cant. ${ }^{\text {es }}$ las entregó Sum. ${ }^{\text {d }}$ al Boticario nombrado, para que este las fuese cobrando, y diese quenta con pago, y sin intermision de otra diligenzia, mandó Sumd. a dho. Procur. ${ }^{r}$ diese la quenta del producto de dha. Botica, desde la ultima tomada por el P. Prov. ${ }^{\text {al }}$ y en su cumplimiento (fol. 19) la dió con cargo, y Data.

Y de concluida la zitada quenta, en el dia diez y seis en que se finalizó, declaró dho. Procurador deber dha. Botica al zirujano Carballo de la Villa de Chaves ciento y veinte R. ${ }^{\mathrm{s}}$

En el mismo dia, atendiendo Sumd. a la declaracion dada por dho. Procur. ${ }^{r}$ a lo ultimo de la quenta de Botica, en que bajo juram.$^{\text {to }}$ expresa, no haver quedado cosa alguna que corresponda al Coll. ${ }^{\circ}$ y sus Granjas por estampar, ni lo que se le deve; y que por carta orden de el S. ${ }^{r}$ Capitan Gnrl. de este Reino, se le prev. $^{\mathrm{e}}$ remitiese a dho. Procur. ${ }^{\mathrm{r}}$ a aquella Ciudad para su embarco, mandó despachar orden para el Bagage correspond. ${ }^{\mathrm{e}}$ a fin de hazer dha. remesa, nombrando para su conduzion a d. ${ }^{\mathrm{n}}$ Juan Garzia de Peñalosa; y que respecto, se celebra en dho. dia la feria Mensual de esta villa, se pusiese en venta los Generos de Comerzio, vidrios, y Barros, y otros que se podian malear, fijando Papeletas para la notizia de todos.

En el mismo dia, se hizo Ymbentario del Pescado q. ${ }^{\mathrm{e}}$ se halló en el Aposento de el Rector, en el q. ${ }^{\mathrm{e}}$ p. ${ }^{\mathrm{r}}$ Sumd. se ha resguardado para su custodia, y en el mismo dia se hizo la venta de algunos de dhos. Generos.

En el dia diez y siette, haviendo concurrido los Bagages, entregó Sumd. a las Puertas del Convento de S. ${ }^{\mathrm{n}}$ Fran. ${ }^{\mathrm{co}}$ asociado de dho. Ess. ${ }^{\text {no }}$ y testigos, dho. Procurador al (fol. 20) Conductor nombrado, juntamente un Pasaporte, y nuevezientos R. ${ }^{\mathrm{s}}$ para los gastos en su conduz. ${ }^{\mathrm{n}}$ a la Ciudad de la Coruña, y de puesto en via recta, y emprehendido su marcha, se retiró Sumd., y dho. ess. ${ }^{\text {no }}$ al zitado Coll. ${ }^{\circ}$ a cuio tiempo llegó igualm. ${ }^{\mathrm{e}}$ d. ${ }^{\mathrm{n}}{ }^{\mathrm{J}}$ Joseph Vaz Arrendatario del Curato de $\mathrm{S} .{ }^{\text {ta }}$ Maria de Tamagos ${ }^{69}$, y entregó a quenta de su prometido quatrocientos quarenta y seis r. ${ }^{\mathrm{s}}$ de q. ${ }^{\mathrm{e}}$ Sumd. le dió rezivo.

En el mismo dia acompañado Sumd. de el ess. ${ }^{\text {no }}$ y Ministro prosiguió en la venta de dhos. Generos.

En el zitado dia, pagó Sumd., al criado que fue de Cocina de dho. Coll. ${ }^{\circ}$ ciento doze $\mathrm{r}^{\mathrm{s}}$ y medio, que le devia de sus salarios de que dió recivo.

69 Las casas y viñas que constan desde fol. 219 hasta 311 se hizo toda una pieza de viña antiguamente, la que se llama al viña blanca; y toda ella se aforó año de 1765 con otros bienes, en AHPOu, Clero: Colegio de Jesuitas de Monterrey, lib. 491, ff. 219r-311r. Cfr. Tumbo de la Iglesia de Santa María de Tamagos, 1581-1636, en ibíd., lib. 482. 
En el dia diez y ocho, Sumd. asistido de dho. ess. ${ }^{\text {no }}$, Mro., y testigos, hizo el requento del Omenaje, y Libros de varios Aposentos.

En el zitado dia parezió el fabrica. ${ }^{\text {te }}$ de la Agua-ardiente de la que resultó haverse hecho entre buena, y mala, ocho arrobas medizinales, las que Sumd. entregó al Boticario nombrado, encargandole diese quenta de su producto con la de los demas Generos de Botica y pagó a dho. fabricante veinte y ocho r. ${ }^{\mathrm{s}}$ por los dias ocupados en su fabrica.

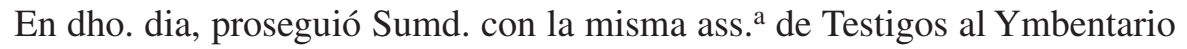
de lo incluso en el Aposento Rectoral.

(fol. 21) Y de finalizado, sin ninguna intermision, continuó Sumd. en el requento, de lo incluso en el Aposento de el P. Vize-Rector.

Y consiguientem. ${ }^{\mathrm{e}}$ y con la ass. ${ }^{\mathrm{a}}$ de las mismas personas, prosiguió en el requento de lo existente en el Aposento del Ministro.

Y a su continuaz. ${ }^{\mathrm{n}}$ al del P. Portero Ph. ${ }^{\text {e Seco. }}$

Y desde este al quarto de salilla. Pasando incontinenti al Aposento que havitaba el P. Predic. ${ }^{\text {or }}$ Aldao recontando todo lo incluso en unos, y otros muy por menor.

En el dia veinte y dos, despachó requisitoria para que la Just. ${ }^{a}$ de Orrios; remitiese hombres para la guarda de este Coll. ${ }^{\circ}$ en atencion de haver cumplido otras Jurisdiz. ${ }^{\text {es }}$ con este cargo.

En el mismo dia, y sin intermision continuó Sumd. con la misma ass. ${ }^{\mathrm{a}}$ en el requento de lo incluso en el Aposento del P. Roque del Rio prefecto de Grammatica.

Continuó igualm. ${ }^{\mathrm{e}}$ en el requento de lo consistente en el Aposento que servia para travajar los Ofiziales.

Prosiguió con la misma ass. ${ }^{a}$ en el requento de lo incluso en el Aposento de el P. Ramon Romero, Maestro de Medianos ${ }^{70}$.

En el dia veinte y quatro, haviendo dado a Sum. ${ }^{\text {d }}$ una Terziana doble que le motivó ponerse en cama, y para efecto de que no se atrasase lo que conduze al pronto exped..$^{\mathrm{e}}$ de su r. ${ }^{1}$ Cometido, suspendió el Ymbent. ${ }^{\circ}$ de lo incluso en los demas Aposentos, y mandó a dho. ess. ${ }^{\text {no }}$ que (fol. 22) interin se restablezia, hiziese requento por ante testigos de las Maderas, y mas Alhajas q. ${ }^{\text {e }}$ se hallaban en los Transitos, Sachristia nueva, y otras partes, y la cal, e igualme. e pagase los salarios devengados en la Caba de viñas, y al Conductor, que havia transportado los Paños a la Coruña.

70 Comunicaciones 1767-1789, de los comisionados y administradores de las Temporalidades de Monterrei, sobre aplicación de bienes, cátedras y otros asuntos de las mismas, en AHN, Clero: jesuitas, leg. 181, nn. 4-5.

Hispania Sacra, Estudios de Edad Moderna, 58

117, enero-junio 2006, 101-141, ISSN: 0018-215-X 
En el mismo dia, pagó dho. ess. ${ }^{\text {no }}$ la caba de viñas de la Granja de Quizanes a los Peones en ella ocupados ${ }^{71}$.

En el dia veinte y cinco, hizo Ymbentario de algunas Maderas, y mas q. ${ }^{\mathrm{e}}$ se halló en el Quarto de Calera; y para saver los ferrados, q. ${ }^{\mathrm{e}}$ havia de Cal, mandó medirla a Juan Labores; y que se compareziese a Ygnazio Bouzán Maestro de Canteria, para que este declarase los Carros de Piedra, q. ${ }^{\mathrm{e}}$ havia labrada, y por labrar para su requento.

En dho. dia, parezió Joseph Sotillo conductor de Paños, entregando el Pasaporte q. ${ }^{\text {e }}$ Sumd. le havia dado, p. $^{\text {a }}$ su remesa a la ziudad de la Coruña, y carta del S. ${ }^{r}$ d. ${ }^{n}$ Geronimo Romero, en que expresa, quedar en su poder las Varas de Paños, q. ${ }^{\mathrm{e}}$ preserve dho. Pasaporte, en cuia vista se le pagaron, quarenta y quatro $\mathrm{r}^{\mathrm{s}}$ por su conduzion.

En dho. dia, pagó el mismo ess. ${ }^{\text {no }}$ zien r. $^{\mathrm{s}}$ de V. ${ }^{\mathrm{n}}$ por la Caba de viñas de la Granja de Villaza en que Sumd. verbalm. . la havia ajustado $^{72}$.

En el dia veinte y seis, hizo dho. ess. ${ }^{\text {no }}$ por ante testigos Ymbentario de las Maderas inclusas en la Sachristia nueva, y de la Piedra, que dho. Ygnazio Bouzan (fol. 23) tasó haver de carros, y numero de Ladrillos; q. ${ }^{\mathrm{e}}$ se hallan en la Azotea, Maroma de la obra, y otras Maderas que se hallaron en un quarto. tejas.

En el mismo dia, y con dha. ass. ${ }^{a}$ continuó el Ymbentario de Maderas, y

En el dia veinte y siete, se declaró ante dho. ess. ${ }^{\text {no }}$ por Juan Labores las tegas de Cal, que havia en la Calera, y le pagó por su trabajo doze $\mathrm{r}^{\mathrm{s}}$ de v. ${ }^{\mathrm{n}}$

En dho. dia asistido dho. ess. ${ }^{\text {no }}$ del Ministro, y tet. ${ }^{\text {os }}$ hizo Ymventar. ${ }^{\circ}$ de las Campanas, Grandes, y de Relox y Maderas del Monumento, y otros omenajes, y protextó consultar todo ello con Sum.

Y en el mismo dia haviendo Sumd. visto los Autos obrados por dho. ess. ${ }^{\text {no }}$ mandó, se reziviese la declaraz. ${ }^{\mathrm{n}}$ de seis hombres panaderos, de el valor que tienen los granos en este Pais, para arreglado a el, formar zedulas para la venta de los existentes en las Granjas de Quizanes ${ }^{73}$, y Villaza, entregándoselos para dho. efecto a los respectivos Caseros, los quales de benefiziados, concurran a dar quenta con pago a Sum. ${ }^{\mathrm{d}}$ y hecho se proceda al Ymbentario de los Estudios, dando Comis. ${ }^{\mathrm{n}}$ p. ${ }^{\mathrm{a}}$ todo ello a dho. Ess. ${ }^{\text {no }}$

71 Venta de Pedro Nobo de una casa cayda, que está en la permuta entre este Coll. ${ }^{\circ}$ y Martínez. Feijóo, dándole á este una casa en Verín, y al Col. ${ }^{\circ}$ una tierra de 19 tegs. al campo de Sousas, termino de Cabreroa, en AHPOu, Clero: Colegio de Jesuitas de Monterrey, lib. 491, ff. 260r-261v.

${ }^{72}$ Libro de foros de San Salvador de Villaza, en AHDOu, Libros parroquiales, caja 27.16.13.

73 Autos de subasta, Data a foro de la Casa, Bodega y Viñedo propio de tempors. sito en el lugar y termino de Quizanes en virtud de Rl. Orn. sobre el asumpto comunicada al cometido de la H. ${ }^{a}$ y Plaza de Monte-Rey. Madrid, 24 de octubre de 1792, en AHPOu, Clero: Colegio de Jesuitas de Monterrey, caja 9959; Libro de foros de San Pedro de Queizás, en AHDOu, Libros parroquiales, caja 43.10.4. 
En el dia veinte y ocho, se rezivió por dho. ess. ${ }^{\text {no }}$ la declaraz. ${ }^{\mathrm{n}}$ de seis hombres vezinos de Monterrey Panaderos, y labradores, por las que resulta, venderse por prezio comun en este Valle la tega de Trigo a seis (fol. 24) Reales y medio, y la de Zenteno a quatro; en cuia vista, se formaron, y fijaron las Zedulas, que se previenen.

En el dia veinte y nueve hizo entrega el mismo ess. ${ }^{\text {no }}$ a Antonio Rodrig. ${ }^{\mathrm{z}} \mathrm{Ca}-$ sero de la Granja de Villaza, de ziento sesenta tegas y media de Trigo, ziento y cinquenta de zenteno, que hizo medir $\mathrm{p} .{ }^{\mathrm{r}}$ un Perito, encargando a dho. Casero vendiese uno, y otro al prezio q. ${ }^{\mathrm{e}}$ ba zitado.

En el dia treinta, pasó dho. ess. ${ }^{\text {no }}$ a ejecutar igual diligencia a la Granja de Quizanes; entregando a Fran. ${ }^{\text {co }}$ Tizón Casero, duzientas quatro tegas, y veinte maquilas de Trigo, y ziento sesenta y una tegas y mediá de zenteno, haziendole saver lo vendiese assi mismo a los prezios, $\mathrm{q} .{ }^{\mathrm{e}}$ ban zitados, y hecho concurriese a dar quenta con pago a Sumd ${ }^{74}$.

En el dia treinta y uno, procedió dho. ess. ${ }^{\text {no }}$ al Ymbentario de las Escuelas, Estudios de Grammatica Philosophia, y Morál, executando todo esto con ass. ${ }^{a}$ y

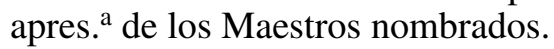

En el mismo dia, hizo Ymbent. ${ }^{\circ}$ del Monte que circunda dho. Coll. ${ }^{\circ}$ por la Parte del Naziente, y Medio dia.

En el primero de Junio, se presentó ante Sumd. d. ${ }^{\mathrm{n}}$ Juan Garzia de Peñalosa, y entregó rezivo del S. ${ }^{\mathrm{r}}$ Romero de haver puesto en el embarcadero de la Coruña al Procur. ${ }^{r}$ de este Coll. ${ }^{\circ}$ y duzientos setenta (fol. 25) y un r. ${ }^{\mathrm{s}}$ y diez y seis maravedis, que le havian sobrado de los gastos hechos en la zitada conduzion, de los nuevezientos $r^{\mathrm{s}}{ }^{\mathrm{s}}$ que le entregó Sumd.; e igualm. ${ }^{\mathrm{e}}$ entregó un Decreto de el S. ${ }^{r}$ Capitan Gral. de este R. ${ }^{\text {no }}$ por el que manda, que de los efectos mas prontos de dho. Coll. ${ }^{\circ}$ se le pague a dho. Conductor a veinte y dos $r^{\mathrm{s}}$ por dia, en cuia vista, le pagó Sumd. a pres. ${ }^{\mathrm{a}}$ de dho. ess. ${ }^{\text {no }}$, duzientos sesenta y quatro r. ${ }^{\mathrm{s}}$ v. ${ }^{\mathrm{n}}$ que importaron los dias ocupados en dha. conduzion.

En el mismo dia, viendo Sumd. el ningun alivio en su enfermedad, para que no se atrasase el pronto expediente de su r. ${ }^{1}$ Comision, mandó, que respecto la satisfaccion que tiene de d. ${ }^{\mathrm{n}}$ Juan Garzia de Peñalosa, asistido de dho. ess. ${ }^{\text {no }}$, hiziese el requento de las Alhajas inclusas en los Aposentos, que restaban $\mathrm{p}^{\mathrm{r}}$ imbentariar; y por lo que respecta a los Libros, y papeles se pusiesen por Abecedario, mientras Sum. ${ }^{\mathrm{d}}$ obtenia razon de la consulta hecha a dho. S. ${ }^{\mathrm{r}}$ Capitan General.

En el mismo dia, dió prinzipio dho. D. ${ }^{\mathrm{n}}$ Juan al Ymbentario del Aposento

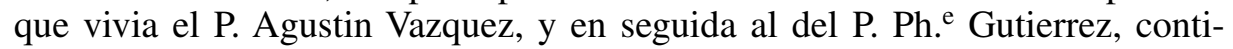

74 Apeo de los bienes del beneficio curado de S. Pedro de Queizás, por ante Gregorio de Grado, escribano de número de Monterrey, 1571, en AHPOu, Clero: Colegio de Jesuitas de Monterrey, lib. 487.

Hispania Sacra, Estudios de Edad Moderna, 58

117, enero-junio 2006, 101-141, ISSN: 0018-215-X 
nuando en el del P. Luis Sandianes, Maestro de Menores, Aposento del numero diez, que se hallaba sin avitazion, el del Juego de Trucos, y Biblioteca.

(fol. 26) Siguiendo una carta orden de treinta de Abril firmada del S. ${ }^{\mathrm{r}} \mathrm{d} .{ }^{\mathrm{n}} \mathrm{Pe}-$ dro Rodriguez Campo-manes por la q. ${ }^{\mathrm{e}}$ pren. ${ }^{\mathrm{e}}$ se haga resumen del Proceso: acompañando un Plan de los Regulares que havia, sus Dependientes, Lugares en que tenian vienes, numero de renta, fanegas en sembradura, Aranzadas de Viñas, reditos de zenso, con lo mas que expresa ${ }^{75}$.

Sigue r. ${ }^{1}$ Ynstrucz. ${ }^{\mathrm{n}}$ de dos de Maio, sobre la forma de los Depositos de Caudales, de la Comp. ${ }^{\mathrm{a}}$, y Copia de la Ynstruz. ${ }^{\mathrm{n}}$ de Catorze de Maio, sobre el modo de pagar Alcavalas, por los Vienes de los Regulares, y a su continuazion, se halla Carta orden del Ex. ${ }^{\mathrm{mo}} \mathrm{S}^{\mathrm{r}}$ Conde de Aranda, de veinte de Maio, sobre lo mismo.

Sigue otra de dho. S. ${ }^{r}$ Capitan Gral. de veinte y seis de dho. Mes, por la que incluie la Copia de dha. Ynstrucz. ${ }^{\mathrm{n}}$ sobre las zitadas Alcavalas.

En el dia quatro de dho. mes de Junio, mandó Sumd., con vista de todo lo que ha zitado, y hallarse mejorado de su dolencia, formar ordenes, para q. ${ }^{\mathrm{e}}$ las Justiz..$^{\mathrm{s}}$ donde hay deudores, en sus Jurisdiziones, a dho. Coll. ${ }^{\circ} \mathrm{y}$ su Botica, les hiziese saver, a los natur. ${ }^{\mathrm{s}}$ de sus Domicilios a fin de que concurriesen a pagar sus devitos ${ }^{76}$; e igualm. ${ }^{\mathrm{e}}$ se hiziese saver a un Herrero, trajese a Sumd. dos cerraduras con sus llaves, a efecto de ponerlas en las dos Arcas en que se hallan las Alhajas de plata, y Vasos Sagrados de Yglesia para con nuevo reconocim. ${ }^{\text {to }}$ q. ${ }^{\mathrm{e}}$ presencie el Parrocho, entregar las dos llaves, al Procur. ${ }^{r}$ sindico Personero de esta (fol. 27) Jurisdizion, y en interin no tenia Sumd. resoluz. ${ }^{n}$ de la Consulta a dho. S. ${ }^{r}$ Cap. $^{n}$ Gral. sobre la . $^{1}$ Provis. $^{n}$ del Consejo de veinte y tres de Abril, que no ha rezivido para el methodo del Ymbentario de Libros, se pusiesen por Abecedario para su mas pronto Ynventario; no obstante de tenerlo hecho de los inclusos en los mas de los Aposentos.

En el dia diez, se concluió el poner dhos. Libros por Abecedario, haver formado, y remitido a las Just. ${ }^{\text {as }}$ las ordenes que se expresan.

En el mismo dia, se vendieron varios generos, y estamparon los vendidos en otros diferentes, y se notificó al Herrero hiziese las dos zerraduras, y llaves para poner en las Arcas que se zitan.

En el nominado dia, y por la noche de el, rezivió Sumd. copia de la r. ${ }^{1}$ Ynstrucz. ${ }^{\mathrm{n}}$ de siete de Abril, y la de veinte y tres de dho. Mes, sobre el Ymbentario

75 Foros, arriendos, permutas, ventas y censos, en AHPOu, Clero: Colegio de la Compañía de Jesús de Monterrei, caja 9951; Apeos, en ibíd., caja 9953; Prorrateos, en ibíd., caja 9954; Ejecutorias, siglos XVI y XVII, en ibíd., caja 9955; Ejecutorias, en ibíd., caja 9956.

76 Recibos 1768-1782, de pagos hechos por diversos conceptos por las Temporalidades, en AHN, Clero: jesuitas, leg. 807, n. 27. 
de Libros, authorizados de Agustin Picado, Barela, ess. ${ }^{\text {no }}$ de numero en la Ciudad de la Coruña, su fha. en seis de dho. Mes de Junio, que dirigió a Sumd. el zitado s. ${ }^{\mathrm{r}}$ Capitan Gral. en virtud de la Consulta referida, a la q. ${ }^{\mathrm{e}}$ dió motivo la notizia Subministrada a Sumd., p. ${ }^{\mathrm{r}}$ el Conductor de el Procur. ${ }^{\text {or }}$ a buelta de su conduzion.

En el dia Onze, mandó Sumd., con vista de las dos R. ${ }^{\mathrm{s}}$ Ynstrcz. ${ }^{\mathrm{s}}$ formar Edictos, y fijarlos en las partes publicas de varios lugares, para que teniendo qualq. ${ }^{\text {ra }}$ Persona caudales en confianza, (o p. ${ }^{\mathrm{r}}$ otro motivo) de los (fol. 28) Regulares, los declarasen, bajo la pena de confiscaz. ${ }^{\text {n; }}$ y que respecto no hay literatos en esta villa para la inteligencia de Libros, se pasase recado urbano al R. P. Guardian de el Convento de S. ${ }^{\mathrm{n}}$ Fran. ${ }^{\text {co }}$ de ella, para q. ${ }^{\mathrm{e}}$ se sirviese declarar, digo señalar quatro Religiosos de los mas aviles para dho. Ministerio, con lo mas que relaziona ${ }^{77}$.

En el mismo dia, se pasó dho. recado politico al estipulado P. Guardian, quien fue servido señalar para dho. ministerio a quatro Religiosos de los Leydos, é inteligentes en el reconocimiento de Libros; y papeles, los quales concurririan a dar principio a dha. Ynspecz. ${ }^{\mathrm{n}}$ en el dia catorze del prenominado Mes de Junio.

En el preescripto dia; se hizo saver a D. ${ }^{n}$ Manuel Perez de Limia, vezino de Verin persona abil para dho. ministerio, concurriese a el en el zitado dia catorze $^{78}$.

En el dia doze, se pagó al Criado que fue de mulas de este Coll. ${ }^{\circ}$ quinientos treze $\mathrm{r}^{\mathrm{s}} \mathrm{y}$ once mrs. que se le devian de sus salarios.

En dho. dia, se pagó al Medico de el Coll. ${ }^{\circ}$ quinientos $r^{\mathrm{s}}{ }^{\mathrm{s}}$ que le devia de sus salarios.

En el mismo dia se pagó a dho. Medico por los dias ocupados en el Ymventario de Botica, y tasa de rezetas treszientos sesenta $\mathrm{r}^{\mathrm{s}}$

En dho. dia, atendiendo Sumd. a hallarse ocupado, y para dar prinzipio al Ynventario de Libros, y otras deligencias prezisas, nombró p. ${ }^{\mathrm{r}}$ Administrador, y Cobrador (fol. 29) de las Deudas de dho. Coll. ${ }^{\circ}$ a d. ${ }^{\mathrm{n}}$ Juan Garzia de Peñalosa, q. ${ }^{\mathrm{n}}$ al mismo tiempo, prosiga en la venta de vino, y cuide de las viñas.

\footnotetext{
77 Expedientes 1769, sobre el envío a Madrid de cuentas y autos de extrañamiento, oposición a Cátedras, almonedas, aplicación de la Iglesia y Colegio, y rentas a los religiosos de San Francisco, en ibíd., leg. 807, nn. 1-18.

78 Copia de Cuentas dadas por Dn. Juan García de Peñalosa Administrador de efecttos de Temporalidades a que acompaña un testimonio de algunas Rs. Ordenes, y Documentos de su Justificazion por los años y fruttos de 1768 y 1769, en AHPOu, Clero: Colegio de Jesuitas de Monterrey, caja 9960, f. 12r. Un informe de este tipo lo elabora ininterrumpidamente entre 1768 y 1780. Cfr. ibíd., caja 9961, para las Temporalidades comprendidas entre 1780 y 1800.
} 
En el mismo dia, se pagaron ciento cinquenta y seis R. ${ }^{\mathrm{s}}$ que devia el Coll. ${ }^{\circ}$ de salarios a Manuel Fernz.

En el zitado dia, se pagaron cinquenta . $^{\mathrm{s}}$ que se devian de salarios a Barme Abelenda Manzebo q. ${ }^{\mathrm{e}}$ fue de la Botica de este Coll. ${ }^{\circ}$

En el mismo dia, se presentó a Sumd. por los Congregantes de la del S. ${ }^{\mathrm{r}} \mathrm{S} .{ }^{\mathrm{n}}$ Jph. petizion, pidiendo se les entregasen las Alhajas, y efectos de dha. Congregazion por ser comprados con dinero suio, a que se decretó no haver lugar y acudiesen a la superioridad; y q. ${ }^{\mathrm{e}}$ para ello se le diese testim. ${ }^{\mathrm{o}}$

En dho. dia, se dio prinzipio al Ymbentario de Libros, papeles, é Ynstrum. ${ }^{\text {os }}$ correspond. ${ }^{\mathrm{s}}$ a la obra pia titular de Grijoá, que se finalizó en el dia veinte y ocho de dho. mes de Junio: a cuio Ymbentario sigue carta orden del Ex. ${ }^{\text {mo }} \mathrm{S} .{ }^{\mathrm{r}}$ Conde de Aranda de fha. de seis de dho. mes de Junio, por la que manda remitir el Procur. ${ }^{\text {or }}$ de este Coll. ${ }^{\circ}$ a Carthagena.

En dho. dia veinte y uno con vista de la horden prezedente, y haverse remitido el Procur. ${ }^{\text {or }}$ de este Coll. ${ }^{\circ}$ en el dia diez y seis de Maio a la Ciud. ${ }^{\mathrm{d}}$ de la Coruña, m. ${ }^{\text {do }}$ Sum. ${ }^{\mathrm{d}}$ juntarla a los autos; y que a su continuaz. ${ }^{\mathrm{n}}$ se probeiese (fol. 30) lo q. ${ }^{\mathrm{e}}$ fuese ocurriendo en el expediente de su r. ${ }^{1}$ Comision interin se finalizaba el Ymbentario de la Obra pia de Grijoá ${ }^{79}$, y assi mismo, se compareziese a Ygnazio Bouzan Maestro de Canteria para q. ${ }^{\mathrm{e}}$ reconociese en que estado se hallaba la Cal por si se podia conservar, o proxima a perderse.

En el dia veinte y dos comparezió dho. Bouzan y pasó al zitado reconocimiento de Cal, y bajo juramento q. ${ }^{\mathrm{e}}$ hizo, declaró, que la que se halla existente en el quarto de Calera está muy dereriorada, y proxima a podrirse por la cantidad que tiene de zeniza, y humedad que rezive de el terreno, por lo que careze de benefizio, y se puede vender la tega lo mas caro a cinco quartos, y la mas que se halla en masa, y con mezcla la dió por inutil.

En cuia vista, y para q. ${ }^{\mathrm{e}}$ no deteriore dha. cal de modo que en lo adelante no haia q. ${ }^{\mathrm{n}}$ la compre $\mathrm{m} .{ }^{\text {do }}$ Sumd. fijar zedulas para su venta protextando rezivir las posturas q. ${ }^{\mathrm{e}}$ se hiziesen a ella.

En el dia veinte y quatro, pagó Sum. ${ }^{\mathrm{d}}$ al zirujano de el Coll. ${ }^{\mathrm{o}}$ sesenta y ocho r. ${ }^{\mathrm{s}}$ y medio que se le devian de sus salarios.

En el dia veinte y cinco, haviendo concurrido ante Sumd. el R. P. Guardian de el Convento de S. ${ }^{\mathrm{n}}$ Fran. ${ }^{\mathrm{co}}$ hizo postura a dha. Cal poniendo la tega a diez y nueve mrs, y por no haver otra persona q. ${ }^{\mathrm{e}}$ la mejorase, y temer su perdizion se la remató Sumd., y aprontó quatroz. ${ }^{\text {tos }}$ quarenta $\mathrm{r}^{\mathrm{s}}$ y treinta y un mrs. que a dha. postura (fol. 31) importaron las setezientas ochenta y nueve tegas de dha. cal.

79 Obra Pía de Grixoá y otras: Escritura de fundación de Grixoá. Memorial de censos de la obra pía. Censos de sacristía, pleitos, capilla, huérfanas, quiebras, estudiantes, en ibíd., caja 9957; Obra Pía de Grixoá. Censos de parientes, en ibíd., caja 9958. 
En el dia veinte y ocho, atendiendo Sum. ${ }^{\mathrm{d}}$ a lo preven. ${ }^{\mathrm{o}}$ en el Capitulo 6. de la R. ${ }^{1}$ Ynstrucz. ${ }^{\mathrm{n}}$ de siete de Abril, m. ${ }^{\text {do }}$ formar testim. ${ }^{\circ}$ de la ropa de cama, y mesa q. ${ }^{\mathrm{e}}$ se hallo existente en dho. Coll. ${ }^{\mathrm{o}}$ y de la remitida a la Ciud. ${ }^{\mathrm{d}}$ de la Cor. ${ }^{\mathrm{a}}$ p. ${ }^{\mathrm{r}}$ orden de dho. S. ${ }^{\mathrm{r}}$ Cap. ${ }^{\mathrm{n}}$ Gral. para dirigirlo al ex. ${ }^{\mathrm{mo}} \mathrm{S} .{ }^{\text {or }}$ Conde de Aranda, y a su continuaz. ${ }^{\mathrm{n}}$ consta haverse form. ${ }^{\mathrm{do}}$

En dho. dia, mandó Sum. ${ }^{\mathrm{d}}$ que respecto de haverse finalizado el Ymbentario de los Pap. ${ }^{\text {s }}$ conzernientes a la obra pia de Grijoá, se procediese al requento de los q. ${ }^{\mathrm{e}}$ se hallan en un Cajon en el Aposento Rectoral pertenez. ${ }^{\text {tes }}$ a las Vacantes de los curatos del Coll. ${ }^{\mathrm{o}} \mathrm{y}$ hecho al de las Alhajas correspond. ${ }^{\mathrm{s}}$ a la Congregaz. ${ }^{\mathrm{n}}$ de S. ${ }^{\mathrm{n}} \mathrm{Jph}^{80}$.

En dho. dia veinte y ocho se dió prinzipio al Ymbentario de los pap..$^{\mathrm{s}}$ correspond. ${ }^{\mathrm{s}}$ a las Vacantes de los Zitados Curatos ${ }^{81}$.

En el mismo dia se presentó p. ${ }^{r}$ D. ${ }^{\mathrm{n}}$ Pedro Perez Vezino de Verin, como poder haviente de $\mathrm{d}^{\mathrm{n}}{ }^{\mathrm{J}}$ Joseph Rubio vezino de Rio seco, pedimentos, representando a Sumd. q. ${ }^{\text {e }}$ este Coll. ${ }^{\circ}$, le estaba deviendo, mil duzientos cinquenta y nueve r. $^{\mathrm{s}}$ y tres quartillos, resto de varias Mercadurias que le havia remitido, segun resulta de la quenta que con dho. poder presentó, a q. ${ }^{\text {e }}$ se decretó no haver lugar a la paga de dha. Cant. ${ }^{\mathrm{d}}$ sin embargo de constar ser zierta dha. deuda; y que acudiese a la superioridad, para lo qual (fol. 32) se le diese testim. ${ }^{\circ}$ queriendolo.

Y sigue una carta de diez y nueve de dho. mes, firmada de el Liz. ${ }^{\text {do }}$ d. ${ }^{\mathrm{n}}$ Gaspar de Losada Quiroga vezino de Monforte, por la que incluie a Sum. ${ }^{\mathrm{d}}$ Pasaporte con un Pliego, que por equibocaz. ${ }^{\mathrm{n}}$ fue parar a sus manos; y lo sigue dho. Pliego de treze de dho. Mes, firmado del ex. ${ }^{\text {mo }}$ S. ${ }^{r}$ Conde de Aranda, en el que remite a Sumd. Pasaporte en blanco, para la remesa a Carthagena: cuio pasaporte se halla subsiguiente, y firmado de dho. S. ${ }^{r}$ Ex. ${ }^{\text {mo }}$ con los blancos q. ${ }^{\text {e }}$ contiene.

Y a la misma continuaz. ${ }^{\mathrm{n}}$ se halla carta orden del S. ${ }^{\mathrm{r}}$ D. ${ }^{\mathrm{n}}$ Pedro Rodrig. ${ }^{\mathrm{z}}$ Campomanes, con fha. de doze de dho. Mes, sobre la eleccion de Casa Diezmera en las haziendas de los Regulares; y que solo se pague la cota fija, que estos asta aora lo hazian.

Sigue un testim..$^{\circ}$ dado por Nicolas Vazquez de Puga, y Cordido Notario, vezino de Orense como Comisionado, de los Arrendadores de la Casa maior Diez-

\footnotetext{
80 Son interesantes las referencias que aparecen en los libros de dos asociaciones religiosas pertenecientes a la parroquia de A Nosa Dona das Neves de Grixoá: Libro de la cofradía de Nuestra Señora de las Nieves de Grixoá, en AHDOu, Libros parroquiales, caja 14.6.9.I; y Libro de la Hermandad de San Gregorio Magno de Grixoá, en ibíd.., caja 14.6.8.I.

81 Tumbo, o Quaderno de Escripturas / pertenezientes a la Fundazion de este Co- / legio de la Compañía de Jhs. de Monterrey, y agregaz'. I de sus Curatos, Concordias, y Partijas con los Abades / de ellos, y mas, que constan de el Yndize, puesto en la / oja siguiente; uno, y otro compuesto, y arreglado. / Año de 1766, en AHPOu, Clero: Colegio de Jesuitas de Monterrey, caja 9950.
} 
mera, pretendiendo, el q. ${ }^{\mathrm{e}}$ Sum. ${ }^{\mathrm{d}}$ consintiese la elecz. ${ }^{\mathrm{n}}$ de la Casa de el Coll. ${ }^{\mathrm{o}}$ en el lugar de Quizanes; en cuia diligenzia, consta haver dado p. ${ }^{\mathrm{r}}$ parte a S. M. (Dios le G. ${ }^{\text {de }}$ ) o el S. ${ }^{r}$ Presidente de Castilla; y que se le diese Copia del Despacho, y su respuesta.

En dho. dia veinte y ocho, mandó Sumrd. (fol. 33) todo lo q. ${ }^{\mathrm{e}}$ ba zitado, a los autos, y q. ${ }^{\mathrm{e}}$ se tuviese presente para los efectos q. ${ }^{\mathrm{e}}$ huviese lugar.

En el dia veinte y nueve, se hizo Ynvent. ${ }^{\circ}$ de las Alhajas pertenez..$^{\mathrm{s}}$ a la Congregaz. ${ }^{\mathrm{n}}$ del Patriarcha S. ${ }^{\mathrm{n}} \mathrm{Jph}, \mathrm{q} .{ }^{\mathrm{e}}$ se hallan en el Aposento del P. ${ }^{\mathrm{e}}$ Manuel del Barrio, Maestro de Moral.

En el dia prim. ${ }^{\circ}$ de el Mes de Julio, teniendo Sumd. ${ }^{d}$ pres. ${ }^{\text {te }}$ lo mandado $p .{ }^{\mathrm{r}}$ el $\mathrm{S}^{\mathrm{r}}{ }^{\mathrm{E}}$ fiscal de S. M. en Carta de 30 de abril, hizo comparezer delante si a dos hombres expertos de el lug. ${ }^{\mathrm{r}}$ de Villaza, y bajo juram. ${ }^{\text {to }}$ declararon los $\mathrm{V}^{\text {es }}$ raizes, q. ${ }^{\mathrm{e}}$ este Coll. ${ }^{\circ}$ tiene en el termo de dho. lugar, y labraba $\mathrm{p} .{ }^{\mathrm{r}}$ si mismo, o traia en arriendo con sus Demarcaz. ${ }^{\mathrm{s}}$ y sembraduras ${ }^{82}$.

En el dia dos de dho. Mes, para efecto de hazer igual requento de los V. ${ }^{\text {es }}$ raizes q. ${ }^{\mathrm{e}}$ dho. Coll. ${ }^{\circ}$ tiene en el lugar de Quizanes, y otras situaz. ${ }^{\mathrm{s}}$ correspond. ${ }^{\mathrm{s}}$ a aquella Granja, hizo venir delante si a dos hombres inteligentes, é idoneos de dho. lugar q. ${ }^{\text {e }}$ los havian traido en arr. ${ }^{\text {do }}$ algun tiempo; y bajo juram. ${ }^{\text {to }}$ declararon dhos. V. ${ }^{\text {es }}$ con sus sembraduras, y demarcaz. ${ }^{\mathrm{s}}$

En el dia quatro de dho. Mes, parezió ante Sum. ${ }^{\mathrm{d}}$ el Casero de Villaza, exponiendo haver finalizado la venta de los Granos, q. ${ }^{\mathrm{e}}$ se le havian entregado; cuio Ymporte compone la Cant. ${ }^{\mathrm{d}}$ de un mil seiscientos quarenta y tres $\mathrm{r}^{\mathrm{s}}{ }^{\mathrm{y}}$ ocho mrs, q. entregó a Sumd.

En el dia cinco, comparezió assi mismo el Casero de la Granja de Quizanes, y entregó a Sumd., un mil treszientos y treinta r. ${ }^{\mathrm{s}}$ p. ${ }^{\mathrm{r}}$ el valor de duzientas quatro tegas, y veinte maq. ${ }^{\mathrm{s}}$ de Trigo, y seiszientos quarenta y seis $r .{ }^{\mathrm{s}} \mathrm{v} \cdot{ }^{\mathrm{n}} \mathrm{p} .{ }^{\mathrm{r}}$ el de ciento sesenta y una tegas y m. ${ }^{\mathrm{a}}$ de zenteno, que se (fol. 34 ) le havian entregado, para su venta, que ambas partidas componen la Cant. ${ }^{\mathrm{g}}$ de un mil nuezientos setenta y seis r. ${ }^{\text { v. }}{ }^{\mathrm{n}}$ q. ${ }^{\mathrm{e}}$ Sumd. rezivió.

En dho. dia, comparezió Manuel Losada Herrero con las dos zerraduras, y llaves, para ponerlas en las dos Arcas, q..$^{\mathrm{e}}$ incluien las Alhajas de Yg. ${ }^{\mathrm{a}}$, y se le pagó veinte r. ${ }^{\mathrm{s}}{ }^{\mathrm{v}}{ }^{\mathrm{n}}{ }^{\mathrm{p}} .{ }^{\mathrm{r}}$ su coste.

En el dia seis en atenzion de haver concurrido las ordenes remitidas a las Justizias de los Domizilios donde hay Deudores para su publicaz. ${ }^{\mathrm{n}}$ mandó

82 Cfr. Tumbo viejo de Villaza o "Libro Memorial, donde se asientan las voces y cabezas que se nombran de los fueros, que se pagaban al monasterio de San Salvador de Villaza desde el anno de mill y quinientos y setenta y tres en adelante», 1573, en AHPOu, Clero: Colegio de Jesuitas de Monterrey, lib. 483; Tumbo primero o nuevo de la Abadía de San Salvador de Villaza. Siglo XVI, en ibíd., lib. 484; Tumbo segundo de San Salvador de Villaza, 1593, en ibíd., lib. 485. 
Sum. ${ }^{\mathrm{d}}$ juntarlas a los autos; y que sin embargo de la ass. ${ }^{\mathrm{a}} \mathrm{q} .{ }^{\mathrm{e}}$ se necesita tener con los Religiosos, y mas q. ${ }^{\mathrm{e}}$ se hallan en el Ynventar. ${ }^{\mathrm{o}}$ de Libros, p. $^{\mathrm{a}} \mathrm{q}^{\mathrm{e}}{ }^{\mathrm{e}}$ no se atrase el exped. ${ }^{\mathrm{e}}$ de el r. ${ }^{1}$ Cometido, mandó q. ${ }^{\mathrm{e}}$ el ess. ${ }^{\text {no }}$ con el Ofizial, forme en las horas q. ${ }^{\mathrm{e}}$ tenga de tpo. en Borrador el memorial, y Plan q. ${ }^{\mathrm{e}}$ se manda $\mathrm{p} .{ }^{\mathrm{r}} \mathrm{Car}-$ ta de Treinta de Abril de el S. ${ }^{r}$ Fiscál.

Siguen las hord. ${ }^{\mathrm{s}}$ dirigidas a las Just. ${ }^{\mathrm{s}}$ p. ${ }^{\mathrm{a}}$ la cobranza de devitos; y q. ${ }^{\mathrm{e}}$ han debuelto en virtud de lo en ellas expresado, y en la remitida a la Just. ${ }^{a}$ de Viana, que se halla a lo ultimo de ellas, consta haverse pagado en dho. dia cinco a su conductor, doze r. ${ }^{\mathrm{s}}$ v. $^{\mathrm{n}}$ ajustado por dha. Just. ${ }^{\mathrm{a}}$ en esta Cant. ${ }^{\mathrm{d}}$

En el dia diez parezió ante Sumd. D. ${ }^{\mathrm{n}}$ Manuel Salgado, Capellan, y Adm. ${ }^{\text {or }}$ de las obras pias titulares de Grijoá, en virtud de Propio, y carta q. ${ }^{\mathrm{e}}$ se le remitió; y en el mismo dia se le tomó la quenta de dha. Administrazion por lo correspod. ${ }^{\mathrm{e}}$ al ano pasado de sesenta y seis, y resultó (fol. 35) Salir alcanzado en tres mil quatrozientos veinte $\mathrm{r}^{\mathrm{s}}$ y treze mrs $\mathrm{V} .^{\mathrm{n}}$ a favor de dha. Obra pia; ademas de quatromil quar. ${ }^{\text {ta }} \mathrm{y}$ tres $\mathrm{r}^{\mathrm{s}}$ y veinte y seis mrs. q. ${ }^{\mathrm{e}}$ dió existentes en manos de primeros Contribuientes, y zensos litigiosos ${ }^{83}$.

En quinze de dho. Mes; atendiendo Sumd. a lo mandado p. ${ }^{\mathrm{r}}$ las r. ${ }^{\mathrm{s}}$ Ynstrucz. ${ }^{\text {es }}$ sre. la entrega de llaves de las Alhajas de Yglesia al Procur. ${ }^{\mathrm{r}}$ sindico Per-

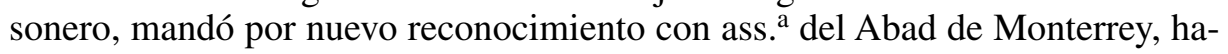
zer dha. entrega; y q. ${ }^{\mathrm{e}}$ respecto en la Yglesia de este Coll. ${ }^{\circ}$ que daran $\mathrm{p}^{\mathrm{r}}$ Ymventariar las Ymagenes de Santos, y otros adornos, se hiziese con la ass. ${ }^{\text {a }}$ de dho. Abad, y test. ${ }^{\mathrm{s}}$

En el mismo dia, hizo Sum. ${ }^{\mathrm{d}}$, con ass. ${ }^{\mathrm{a}}$ de d. ${ }^{\mathrm{n}}$ Pedro Barreda Zambrano Parrocho de esta Villa, y test. ${ }^{\mathrm{s}}$ de excepz. ${ }^{\mathrm{n}}$ reconocim. ${ }^{\text {to }}$ de las Alhajas de plata, y vasos sagrados de la Yglesia de este Coll. ${ }^{\circ}$ y entrega de las dos llaves hechas de nuevo, puestas en las dos arcas donde se hallan dhas. Alhajas, a dho. ess. ${ }^{\text {no, }}$, quien en el pres. $^{\mathrm{e}}$ año es Procur. ${ }^{\text {or }}$ sindico Personero de dha. V. ${ }^{\mathrm{a}}$ su Jur. ${ }^{\text {on }}$ y Condado, quedandose Sumd. con las otras dos, para su maior custodia ${ }^{84}$.

En el dia diez y seis, procedió Sum. ${ }^{\mathrm{d}}$ con ass. ${ }^{\mathrm{a}}$ de dho. Abad, y test. ${ }^{\mathrm{s}}$ al Ymbentario de las Ymagenes de Santos, Quadros, y otras cosas inclusas en la Yg. ${ }^{a}$ de este Coll. $^{\circ}$, y de q. ${ }^{\text {e }}$ no se havia hecho requento al tiempo de el de las Alhajas, y Ornamentos, p. ${ }^{r}$ tener dha. bien zerrada, y otras cosas q. ${ }^{\mathrm{e}}$ requerian pronto exped. ${ }^{\text {te }}$

83 Expedientes 1768-1769, sobre el Patronato del Mayorazgo de Grijoa, aplicación de bienes del Colegio y otros asuntos de las Temporalidades del mismo, en AHN, Clero: jesuitas, leg. 806, nn. 3-9; y más adelante, Comunicaciones 1789-1819, de los comisionados y administradores de las Temporalidades de Monterrei, sobre aplicación de bienes, Obra Pía de Grijoa y otros asuntos de dichas Temporalidades, en ibíd., leg. 182, nn. 1-3.

${ }^{84}$ Sobre el destino del patrimonio artístico del Colegio de Monterrei, cfr. Instancias 1789-1793, de varias Iglesias, y Conventos, solicitando libros, ornamentos, alhajas y vasos sagrados de las Temporalidades de Monterrei; otras peticiones a las mismas de varios particulares, en ibíd., leg. 807, nn. 19-25.

Hispania Sacra, Estudios de Edad Moderna, 58

117, enero-junio 2006, 101-141, ISSN: 0018-215-X 
En el dia diez y siete, pagó Sumd. a Anselmo (fol. 36) Rodriguez Pastor que fue de Carneros en este Coll. ${ }^{\circ}$ cinquenta y dos $r^{\mathrm{s}}$ y quinze mrs. que se le devian de sus salarios.

En dho. dia se pagó assi mismo p. ${ }^{\mathrm{r}}$ Sumd. a D. ${ }^{\mathrm{n}}$ Santiago Guerra Boticario, ciento ochenta r. ${ }^{\mathrm{s}}$ p. ${ }^{\mathrm{r}}$ los dias q. ${ }^{\mathrm{e}}$ ocupó en el Ymbentario de Botica, y Tasa de rezetas.

En el dia veinte prometió Sum. ${ }^{\mathrm{d}}$ un auto para q. ${ }^{\mathrm{e}}$ se compulsase la Bula de la congregazión de S. ${ }^{\mathrm{n}}$ Joseph respecto de que el Rettor de ella y mas congregantes avian pedido la entrega de sus efectos, y por no hallarse con Jur. ${ }^{n}$ Sum. ${ }^{\mathrm{d}}$ se les mandó acudiesen a la subperioridad, y para ello se librase testim. ${ }^{\circ}$ con ynsercion de dha. Bulla. lo que no han ejecutado.

Se compulso dha. Bulla y a su Continuazion se dio razon de la Congregazion de nra. señora de la conzepcion:

En el dia veinte y quatro treinta y seis $\mathrm{r}^{\mathrm{s}}$ de v. ${ }^{\text {on }}$ a Jph. Sotelo como marido de D. ${ }^{a}$ Manuela Machado Costurera del Colegio.

En dho. dia Provehio sum. ${ }^{\mathrm{d}}$ auto mandando que respecto no se hallava en lo actuado ess. ${ }^{\text {ra }}$ del Zenso o compra de los 19 lugares que este Colegio hizo en Roma, se regitrase el archivo, y no la hallando, se hiziese de un mazo de Cartas Giradas sobre los quindenios que se pagan en dha. Corte Romana, por los Curatos deste Colegio.

En el dia Veinte y cinco se halla la deligencia de no averse hallado dha. Ess. ${ }^{\text {ra }}$, y en el mazo de Cartas (fol. 37) se hallaron cinco, escritas en Roma firmadas de Jayme Andres Procurador del Colegio en aquella Corte, dando noticia de la Compra de los 19 lugares de Monte S. ${ }^{n}$ Pedro, las que se arrimaron acontinuazion de dha. delig. ${ }^{\mathrm{a}}$ y se mandó formar testimonio en relacion de ello para noticiarlo a S. E. el Señor Presidente del Real Consejo, como se ejecutó.

En el dia Veinte y seis, compareció $\mathrm{D}^{\mathrm{n}}$ Juan Garcia Administrador de los vienes deste Coll. ${ }^{\circ}$ dando razon de lo gastado en el venefizio de las viñas trasiega de vino y limpieza de cubas, que asciende, lo por el suplido a quatrocientos treintaycinco $\mathrm{r}^{\mathrm{s}}$ y quatro mrs., ademas de lo que se le ha subministrado por sum. ${ }^{\mathrm{d}}$ de los efectos Ynclusos en este Coll. ${ }^{\mathrm{o}}$

En el dia veinte y siete se pagaron D. Manuel Rodriguez treinta . $^{\mathrm{s}} \mathrm{V} .{ }^{\mathrm{n}}$ que le devia el colegio de la renta de un Buey. y buelta de un doblon:

En veinte y nueve se formó auto para que un ministro Compareciese a los sugetos que tienen bienes aparzeria de dho. colegio y obra pia de Alonso R. ${ }^{\text {ez }}$ para hazerles saver no los vendan ni Cambien sin orden q. ${ }^{\mathrm{e}}$ se hizo saver.

En treinta de dho. mes se pago a $\mathrm{D}^{\mathrm{a}}$ Maria Montano por el Salario de hazer Vizcochos, dos cientos noventa y ocho r. ${ }^{\mathrm{s}}$ v. ${ }^{\mathrm{n}}$ que (fol. 38 ) le devia el Colegio, Consta de la quenta dada por el Procurador y ajuste en el libro de Asiento. 
En dho. dia asi mismo se pagó a D. ${ }^{\mathrm{n}}$ Mathias Machado trescientos treinta y seis $r^{\mathrm{s}}{ }^{\mathrm{V}} .^{\mathrm{n}}$ que este colegio le devia procedidos de tres dozenas de platos de peltré, y otras tres de servilletas, consta de la quenta dada por dho. Procurador y libro de Deudas.

En treinta y uno se estampo la venta de diferentes Jeneros rematados a varias pers. ${ }^{\text {as }}$ que su ymporte son quinientos y set. ${ }^{\text {ta }}$ rr. $^{\mathrm{s}}$

En primero de Agosto se formó auto p. ${ }^{\mathrm{r}}$ el que se mando entregar a D. ${ }^{\mathrm{n}}$ Juan Garcia de Peñalosa Administrador, los libros Cobradores de foro Zensos, y Deudas ${ }^{85}$ :

Se ejecutó en dho. dia la zitada entrega de libros: Y en el mesmo se pagaron a D. ${ }^{\mathrm{a}}$ Maria Boan treinta ${ }^{\mathrm{s}}{ }^{\mathrm{s}}$ de vellon por el valor de tres tarteras que avia remitido pocos dias antes de la expulsion al Colegio consta de la quenta dada por dho. Procura. ${ }^{\text {or }}$

En dos de dho. mes concurrio Diego Gallego Casero de la Casa de Verin ${ }^{86}$ dando quenta aver vendido las sesenta y seis quartas de Vino que avia llevado de la bodega (fol. 39) deste Colegio pagando su ymporte que lo es de quinientos setenta y siete $r^{\mathrm{s}}$ y seis mrs. de vellon.

En ocho de dho. mes ha concurrido D. ${ }^{\mathrm{n}}$ Juan Garcia de Peñalosa Administrador de los efectos de los regulares, dando quenta del vino que ha vendido de las dos Granjas, y entregado su ymporte que lo es de doce mil nuevecientos veinte y seis R. ${ }^{\mathrm{s}}$ y seis mrs. v. ${ }^{\mathrm{n}}$

Consta asimismo averse admitido posturas a los Curatos de San Salvador de Villaza y S. ${ }^{\mathrm{n}}$ Pedro de Quizanes a las personas que concurrieron a hazerlas, y averse rematado el de Quizanes en Joseph Lorenzo en un mil y Settz ${ }^{\text {os }}$. R. ${ }^{\mathrm{s}}$ Vellon $=\mathrm{Y}$ el de Villaza en Benito Perez de Arriba en la Cantidad de diez mil Ciento sesenta y quatro . $^{\mathrm{s}} \mathrm{v} .^{\mathrm{n}}$

En ocho del mismo mes de Agosto Provehió Sum. ${ }^{\mathrm{d}}$ auto en virtud de carta del Yll. ${ }^{\text {mo }}$ señor D. ${ }^{\mathrm{n}}$ Pedro R. ${ }^{\text {ez }}$ Campomanes para que se Ynforme de que prozeden los devitos que resultan a favor de los regulares, se formo testim. ${ }^{\circ}$ de lo que constava y se remitio con tres Cartas:

En nueve de dho. mes se mandó jirar edictos para que quien quisiere comprar la leña que avia sobrante de la consum. ${ }^{\text {da }}$ (fol. 40) con los Guardas, y Ym-

85 Cuentas 1767-1789, de las Temporalidades de este Colegio, dadas por los administradores de las mismas, en AHN, Clero: jesuitas, leg. 806, nn. 1-2.

${ }^{86}$ Varias escrituras hacen referencia a esta posesión: Venta del suelo de la casa y Bodega de Verin echa por Bernardo Fernández herrador; Fuero perpetuo de dicho suelo hecho por el monasterio de Celanova; Consentimiento para fabricar sobre dicho suelo, la Casa y Bodega; Foro hecho por el monasterio de Celanova a este Colegio por las propiedades sitas en Verín y heredadas de Amaro Rodríguez, en AHPOu, Clero: Colegio de Jesuitas de Monterrey, lib. 491, ff. 320r-321v; 322r-323r; 324r$325 \mathrm{v} ; 326 \mathrm{r}-334 \mathrm{r}$.

Hispania Sacra, Estudios de Edad Moderna, 58

117, enero-junio 2006, 101-141, ISSN: 0018-215-X 
bentario de libro, acudiendo ante sum. ${ }^{\mathrm{d}}$ que se la remateria al maior Postor: consta averse finado.

En el dia diez consta averse finalizado el Ymbentario de libro manu escritos y $\operatorname{cartas}^{87}$.

En el dia onze consta averse pagado a Pedro Marcos Vaamonde seiciento diez y seis R. ${ }^{\mathrm{s}}$ por los salarios que devengó en dho. Ynventario.

En el mismo se pagaron ciento sesenta y ocho r. ${ }^{\mathrm{s}}$ a Alexandro frm. y Mathias Garcia.

Sigue un auto por el que se mandó que D. ${ }^{\mathrm{n}}$ Pedro Perez Vez. ${ }^{\text {no }}$ de la Villa de Verin Apoderado de D. ${ }^{\mathrm{n}}$ Jph Rubio mercader en Rioseco con quien el Colegio seguia sus Correspondiencias; formalizase su demanda como tal apoderado, y Justificase el credito que dho. Colegio le devia de varios Jeneros, y para ello se sacase copia de un Capitulo de la Carta remitida por el Señor fiscal de S. M. se ejecutó, e hizo saver a dho. Apoderado alegó de su justicia, diz. ${ }^{\text {do }}$ que en fuerza de la antigua Correspondencia, avia remitido su parte a dho. Colegio varios generos y por ellos le restaria deviendo un mil doscienttos (fol. 41) Zinquentta y nueve R. ${ }^{\mathrm{s}}$ y veinte y seis mrs $\mathrm{v}^{\mathrm{n}}$ segun resultaria del libro de asientto, quentas dadas por el Procu. ${ }^{\text {or }}$ y las que avia pres. ${ }^{\text {do }}$ con el Poder, las que confrontarian unas con otras, pidio se hiziese cotejo, con lo $\mathrm{q}^{\mathrm{e}}$ tenia Justificado su credito se mandó asi, y hecho salió conteste.

En el dia doze formó sum. ${ }^{\mathrm{d}}$ la quenta de lo que avia gastado con los quatro religiosos y mas sugetos qué avian asistido al Ynventario e yndice General de los libros, manu-escritos, y Cartas y resulta segun consta por menor y diariam. ${ }^{\text {te }}$ settez. ${ }^{\text {os }}$ noventa $\mathrm{R} .{ }^{\mathrm{s}} \mathrm{y}$ treze mrs. Cinq. ${ }^{\text {ta }}$ quartas destino; treinta y siete tegas y m. ${ }^{\mathrm{a}}$ de trigo, y otros Generos de dispensa.

En los treze de dho. mes entregó Antonio R. ${ }^{\text {ez }}$ Casero de la Granxa de Villaza, seiscientos y quatro . $^{\mathrm{s}} \mathrm{v} .{ }^{\mathrm{n}}$ por ciento Zinq. ${ }^{\text {ta }}$ y una tega de zent. ${ }^{\text {no }}$ que sum. ${ }^{\mathrm{d}}$ le avia entregado para su venta.

En dho. dia consta averse entreg. ${ }^{\text {do }}$ al administrador Cien tegas de Zenteno para hazer la vendimia.

En los Catorze de dho. mes de Agosto Consta dar Principio Sum. ${ }^{\mathrm{d}}$ a la quenta de todos los Caudales que hallo existentes al tiempo de la expulsion, Perzivido de (fol. 42) frutos y Jeneros Vendidos que se han rematado en publica al moneda que aszenden a la Cant. ${ }^{\mathrm{d}}$ de veinte y nueve mil setez. ${ }^{\text {os }}$ veinte y quatro $\mathrm{r}^{\mathrm{s}}$ diez y ocho mrs v. ${ }^{\mathrm{n}}$ seg. ${ }^{\mathrm{n}}$ resulta por menor, y se halla a los folios zitados en ella.

87 Cfr. Emilio Duro PeÑa, Papeles privados y libros manuscritos del Colegio de Monterrey, en «Humanidades» XV, 35 (Comillas, 1959), pp. 162-168, donde aparece una relación de los papeles privados hallados en los aposentos de cada uno de los individuos que componen la Casa de Monterrei. 
A cuia continuazion consta lo que ha pag. ${ }^{\text {do }}$ y gastado, como ygualm. ${ }^{\text {te }}$ resulta por menor y folios expresados en sus partidas.

En el dia 13 de Agosto se provehio auto para se saque copia de la fundación de el Colegio, Y se hiziese saver al Administrador nombrado, que para la maior seguridad de lo que entrase en su poder diese las Correspondientes fianzas Y hecho y formado las Capitulaciones se le entregase todo lo que se halla en el Colegio y sus Granjas.

En dho. dia se dio principio a la Compulsa de la fundacion del Colegio y sus Capitulaciones ${ }^{88}$.

En el veinte y dos dio el Administra. ${ }^{\text {or }}$ las suficientes fianzas vajo las Capitulaciones que se le formaron ${ }^{89}$.

En el dia 22 se hizo entrega al Administrador de lo existente en el Colegio y sus Granjas, a excepcion de las llaves de (fol. 43) la Yglesia y Biblioteca.

En dho. dia se puso fee de aver sacado copia de la fianza y capitulaziones y entregadola al Administrador.

En el mismo se mandó por aviso despachar libram. ${ }^{\text {to }}$ a favor de Domingo Diz Panadero para que se le pagaren por el Administrador treinta y siete tegas y media de trigo que suplió para el Ymbentario de los libros y Cartas.

En dho. dia consta averse formado el zitado libramiento y entregadolo a dho. Panadero.

En dho. dia 22 se provehió para que el Boticario del Colegio entregase al Administrador los mrs. que tubiese Cobrado de atrasos, y lo que baia produciendo la Botica, y le diese las quentas quando se lo pida:

En el dia 23 se hizo saver dho. Auto al Boticario y ofrecio cumplir con su thenor.

Sigue la Carta horden del Yll. ${ }^{\text {mo }}$ Señor D. ${ }^{\mathrm{n}}$ Pedro R. ${ }^{\text {ez }}$ Campomanes de 29 de Julio. Y otra del Ex. ${ }^{\text {mo }}$ Señor Capitan Gen. ${ }^{\text {al }}$ deste R. ${ }^{\text {no }}$

A cuia Continuazion se halla un memorial presentado por los Maestros de los estudios y Escuela, representando la continua y puntual Asistencia, y pidiendo se les señale y satishaga lo que que decian aver.

En dho. dia 23 se provehio auto por el que se mandó Juntar todo lo arriba ex-

88 Fundacion y Constituciones del / Colegio de San Juan Bautista / de la Villa de Monterrey que / fundo el Br. Juan de Balderra- / ma Abad de S. Pedro de Flariz / Obispado de Orense. tienen 34 / hojas, alas que van unidas, otras / pequeñas, que son 14. siguese una / carta de S. S. Y. y 22 hojas de $q^{\text {tas. }}$ / de gasto del dho. Colegio, que con $4 /$ al principio componen todas el $/ n .^{\circ}$ de 74 hojas $=$, en AHPOu, Clero: Colegio de Jesuitas de Monterrey, caja 9950.

89 Más información sobre el particular, en Concordia entre el Obpo. de Orense y Conde de Monterrey sobre la fundacion deste Coll. ${ }^{\circ}$, en ibíd., caja 9950, ff. 1r-6r. 
presado (fol. 44) A los autos, y se ynformase del numero de vezinos que ay en los lugares donde tenian vienes los regulares.

En dho. dia se formó el Ynforme de Vezinos que ay en dhos. Lugares.

En el 24 se provehió Auto para que se enquadernarse en pergamino, y rotulasen los autos, Plan y memorial o resumen de ellos con lo mas que expresa; Protestando conducirlos a la Ziu. ${ }^{\mathrm{d}}$ de la Coruña y poder del Ex. ${ }^{\mathrm{mo}}$ señor Capitan Gen. ${ }^{\text {al }}$ deste reino.

En dho. dia probeió sumrd. auto p. ${ }^{\mathrm{a}} \mathrm{q} \cdot{ }^{\mathrm{e}}$ el pres. $^{\text {te }}$ esc. $^{\text {no }}$ pasase a la entrega de los Autos y mrs. q. ${ }^{\mathrm{e}}$ resultan haciendole entrega de ellos.

Es lo q. ${ }^{\text {e }}$ Consta de Autos obra. ${ }^{\mathrm{s}}$ desde el dia 2 de Abril, hasta dho. dia 24 de Agosto y $\mathrm{p} \cdot{ }^{\mathrm{a}} \mathrm{q} .{ }^{\mathrm{e}}$ conste se firma. 